\title{
Chernobyl Lessons Learned Review of N Reactor
}

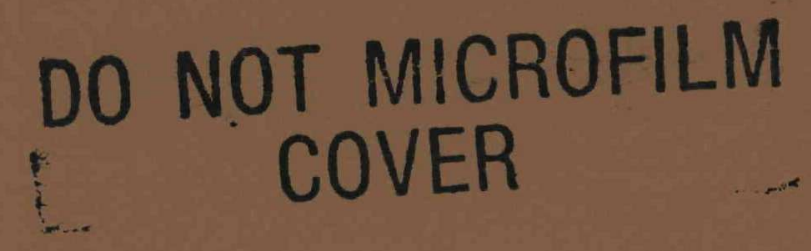

Prepared for the U.S. Department of Energy Assistant Secretary for Defense Programs

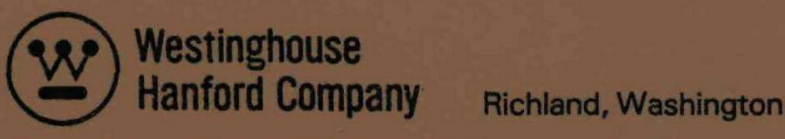

Hanford Operations and Engineering Contractor for the

U.S. Department of Energy under Contract DE-AC06-87RL10930

Patent Status This document cooy, since it is transmitted in advance of patent clearance, is made available in conficience solely for use in performance of work under contracts with the USDOE. This document is not to be published nor its contents otherwise disseminated or used for purposes other than specified above before patent approval for such release or use has been secured. upon request, from the USDOE, Patent Attorney, Richland Operations Office, Richland. WA.

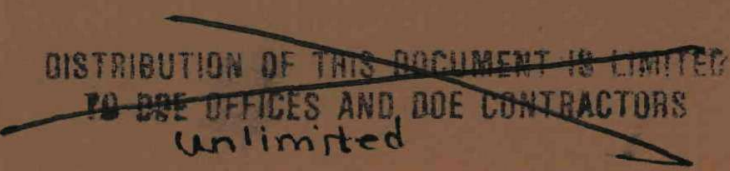




\section{DISCLAIMER}

This report was prepared as an account of work sponsored by an agency of the United States Government. Neither the United States Government nor any agency thereof, nor any of their employees, nor any of their contractors, subcontractors or their employees, makes any warranty, express or implied. or assumes any legal liability or responsibility for the accuracy, completeness, or any third party's use or the results of such

use of any information, apparatus, product, or process

disclosed, or represents that its use would not infringe privately owned rights. Reference herein to any specific commercial product, process, or service by trade name, trademark, manufacturer, or otherwise. does not necessarily constitute or imply its endorsement, recommendation, or favoring by the United States Government or any agency thereof or its contractors or subcontractors. The views and opinions of authors expressed herein do not necessarily state or reflect those of the United States Government or any agency thereof.

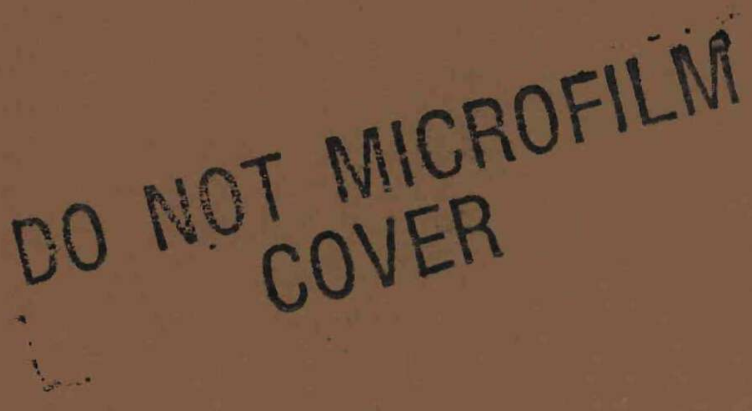




\section{DISCLAIMER}

This report was prepared as an account of work sponsored by an agency of the United States Government. Neither the United States Government nor any agency Thereof, nor any of their employees, makes any warranty, express or implied, or assumes any legal liability or responsibility for the accuracy, completeness, or usefulness of any information, apparatus, product, or process disclosed, or represents that its use would not infringe privately owned rights. Reference herein to any specific commercial product, process, or service by trade name, trademark, manufacturer, or otherwise does not necessarily constitute or imply its endorsement, recommendation, or favoring by the United States Government or any agency thereof. The views and opinions of authors expressed herein do not necessarily state or reflect those of the United States Government or any agency thereof. 


\section{DISCLAIMER}

Portions of this document may be illegible in electronic image products. Images are produced from the best available original document. 


\title{
Chernobyl Lessons Learned Review of N Reactor
}

\author{
E. T. Weber \\ J. P. McNeece \\ R. P. Omberg \\ D. D. Stepnewski \\ Westinghouse Hanford Company \\ R. J. Lutz \\ Westinghouse Electric Corporation \\ Nuclear Technology Services Division
}

R. E. Henry

Fauske and Associates

K. D. Bonser

N. R. Miller

UNC Nuclear Industries

Date Published

October 1987

Date Manuscript Completed

June 1987

Prepared for the U.S. Department of Energy Assistant Secretary for Defense Programs

\section{(2) Westinghouse P.O Box 1970 \\ Hanford Company Richland, Washington 99352}

Hanford Operations and Engineering Contractor for the

U.S. Department of Energy under Contract DE-AC06-87RL10930

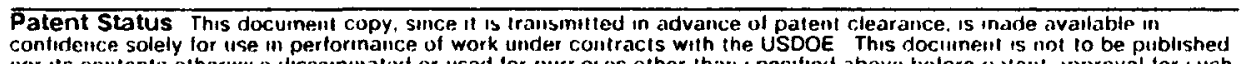
nor its contents otherwise dissernmaled or used for purfoses other than specified above belore pelent approval for such release or use
Rich hland, WA 
- 


\section{CONTENTS}

\section{Page}

Tables

Acronyms

I. SUMMARY

II. COMPARISON BETWEEN N REACTOR AND CHERNOBYL

A. DESIGN FEATURES COMPARISON

B. OPERATING FEATURES COMPARISON

C. CHERNOBYL ACCIDENT DESCRIPTION

III. LESSONS LEARNED REVIEW PROCESS $\quad 23$

IV. INQUIRY AND CONCLUSIONS 26

$\begin{array}{ll}V . & \text { RECOMMENDATIONS }\end{array}$

$\begin{array}{ll}\text { VI. BIBLIOGRAPHY } & 49\end{array}$

\section{DISCLAIMER}

This report was prepared as an account of work sponsored by an agency of the United States Government. Neither the United States Government nor any agency thereof, nor any of their employees, makes any warranty, express or implied, or assumes any legal liability or responsibility for the accuracy, completeness, or usefulness of any information, apparatus, product, or process disclosed, or represents that its use would not infringe privately owned rights. Reference herein to any specific commercial product, process, or service by trade name, trademark, manufacturer, or otherwise does not necessarily constitute or imply its endorsement, recommendation, or favoring by the United States Government or any agency thereof. The views and opinions of authors expressed herein do not necessarily state or reflect those of the United States Government or any agency thereof. 
TABLES

Page

II.I Summary of Key Similarities and Differences

Between $\mathrm{N}$ Reactor and Chernobyl

7

III.1 NRC Issues from Chernobyl Lessons Review

24

III.2 UNC Staff Contributors to Chernobyl Lessons L.earned Review 


\section{ACRONYMS}

$\begin{array}{ll}\text { AR } & \text { Automatic Power Regulating Rod } \\ \text { ATWS } & \text { Anticipated Transient Without Scram } \\ \text { DOE } & \text { Department of Energy } \\ \text { ECCS } & \text { Emergency Core Cooling System } \\ \text { ERC } & \text { Emergency Response Center } \\ \text { EPZ } & \text { Emergency Planning Zone } \\ \text { ERD } & \text { Emergency Response Director } \\ \text { FCI } & \text { Fuel Coolant Interaction } \\ \text { FWHM } & \text { Full Width at Half Maximum } \\ \text { GSCS } & \text { Graphite and Shield Cooling System } \\ \text { IAEA } & \text { Internationa1 Atomic Energy Agency } \\ \text { INPO } & \text { Institute of Nuclear Power Operation } \\ \text { LAR } & \text { Local Automatic Power Regulating Rod } \\ \text { LOCA } & \text { Loss of Cooling Accident } \\ \text { LWR } & \text { Light Water Reactor } \\ \text { NRC } & \text { Nuclear Regulatory Commission } \\ \text { NUSAR } & \text { N Reactor Updated Safety Analysis Report } \\ \text { PCA } & \text { Process Change Authorization } \\ \text { PRA } & \text { Probabilistic Risk Assessment } \\ \text { TMI } & \text { Three Mile Island }\end{array}$




\section{CHERNOBYL LESSONS LEARNED REVIEW OF N REACTOR}

\section{EXECUTIVE SUMMARY}

A broad-base review of the $N$ Reactor plant, design characteristics, administrative controls and responses unique to upset conditions has been completed. The review was keyed to Nuclear Regulatory Commission (NRC)defined issues associated with the Chernobyl accident. Physical features of $\mathrm{N}$ Reactor that preclude an accident like Chernobyl include: lack of autocatalytic reactivity insertion (i.e., negative coolant void and power coefficients) and two separate, fast-acting scram systems. Administrative controls in place at $\mathrm{N}$ Reactor would effectively protect against the operator errors and safety violations that set up the Chernobyl accident. Several items were identified where further near-term action is appropriate to ensure effectiveness of existing safety features:

- Resolve a question concerning the exact point at which Emergency Core Cooling System (ECCS) activation by manual actions should be implemented or deferred if automatic ECCS trip fails. Ensure appropriate revision of the Emergency Response Guides and full communication of the correct procedure to all Operations, Safety and cognizant Technology staff.

- Train reactor operators in the currently recognized significance of the Graphite and Shield Cooling System (GSCS) in severe accident situations and cover this appropriately in the Emergency Response Guides.

- Complete reviews which establish an independent verification that pressure tube rupture will not propagate to other tubes.

Original signed by RJ Lutz \& RE Henry E.T. Weber (WHC) R.J. Lutz (W-NTSD) R.E. Henry (FAI)

The following items address refinements or reinforcements for administrative controls and ongoing activities in the Safety Enhancement Program:

- The provisions and practice for oral approval of Process Change Authorizations (PCAS) should be reviewed to ensure acceptability.

- Operations management should consider implementing a systematic, routine assessment of compliance with procedures by operating personnel, including provision for review of trends indicating unacceptable departure from expected performance. 
- Production Test approval should be reviewed, focusing on final approval responsibility for both Operations and Safety. The current process based on approval signature by 10 to 12 individuals tends to diffuse responsibility.

- Test documentation should state requirements on the minimum qualifications for Test Directors.

- Section 8.0, "Safety Analysis, Potential Hazards, and Special Precautions," of UNI-M-89, SI-6, should be augmented since it does not provide sufficient detail and guidance to ensure uniform and sufficient treatment of safety concerns.

- There should be organizational separation of the test sponsor from the independent safety approval of Production Tests. (This is addressed in organizational restructuring by Westinghouse Hanford Company with contract takeover.)

- Review the range of responsibilities and the possible decision scenarios that might be thrust upon the Shift Manager and his role as Emergency Response Director (ERD) to ensure he has adequate guidance or outside support.

- Provide for review of the inprocess restructuring of the Emergency Response Guides by a peer group experienced in preparation of equivalent procedures for commercial light water reactor (LWR) plants.

- Updated reactor physics codes should be applied to (re)analyze reactivity insertion events identified as key initiators or contributors to the N Reactor Updated Safety Analysis Report (NUSAR) or beyond-NUSAR accident scenarios, including definition of margins to important core damage thresholds. 
WHC-SP-0257

\section{CHERNOBYL LESSONS LEARNED REVIEW OF N REACTOR}

\section{SUMMARY}

The Chernobyl plant Unit No. 4 was destroyed in April 1986 by an energetic power excursion caused by a combination of the Soviet RBMK plant design features and operator disregard of procedures and administrative controls. Because of perceived similarities, i.e., graphite moderated and water cooled, the $N$ Reactor at Hanford has been subjected to a multitude of safety reviews to ensure that the conditions leading to the Chernobyl Unit No. 4 accident cannot occur in $\mathrm{N}$ Reactor. The review covered in this report was performed to evaluate $N$ Reactor on the bas is of our knowledge of the key factors leading to the Chernobyl accident and the lessons learned from it. The dominant conclusion is that the $N$ Reactor design makes it physically impossible to have an autocatalytic reactivity excursion such as the one which destroyed the Chernobyl plant. In addition, $N$ Reactor procedures and practices would preclude operator procedure violations of the kind which set up the Chernobyl accident.

In early 1987, reports of Department of Energy (DOE) and NRC evaluations of the Chernobyl accident became available. This review was based on those reports, which had not been available for previous consultants reviews. The DOE and NRC technical review shows that a positive coolant void reactivity coefficient is characteristic of the RBMK design. Violations of operating and test procedures led to rapid formation of steam in coolant channels, which combined with a slow-acting, ineffective scram system to produce a power excursion to 110 times the normal rating. While some consultants recognized the impossibility of an autocatalytic power excursion in $N$ Reactor, other perceived similarities with Chernobyl are clearly incorrect or irrelevant. It is now known that graphite in the core of the Chernobyl reactor, which represents the most quoted similarity to $\mathrm{N}$ Reactor, did not materially contribute to the occurrence of the accident. Also, all available evidence at this time indicates that hydrogen was probably not a factor in the process that destroyed the reactor. Key differences that separate $N$ Reactor from the possibility of a Chernobyl-type disaster can be addressed in terms of design features, administrative controls, review of accident vulnerability, and emergency response posture.

$N$ Reactor design and safety features that represent key differences from the Chernobyl plant are:

- $\quad \mathrm{N}$ Reactor's design inherently reduces power when the reactor cooling water temperature increases and especially if the cooling water should boil.

- $\quad$ R Reactor has two fast-acting scram shutdown systems, either of which would effectively stop a power excursion. 
- $\quad \mathrm{N}$ Reactor's emergency cooling system is independent of electrical power requirements.

- A second cooling system for the graphite is capable of providing long-term cooling even if both the normal and emergency cooling systems are lost.

- A confinement system, which encloses the entire nuclear steam supply system, retains radioactive material even if an accident occurs. The system incorporates water sprays that would limit or extinguish fires associated with an accident.

Administrative controls required at $N$ Reactor establish the following bas is for confidence in operations:

- There is in place a system with multiple layers of protection between limits set in standard operating procedures and conditions representing a safety risk.

- The operating staff is formally trained with emphasis on adherence to procedures and limits (called Process Standards). Operations management continually reinforces compliance to safety standards.

- Tests performed in the reactor are controlled by rigorous procedures and safety reviews, which ensure that the reactor operator's primary responsibility is plant safety rather than the test.

- No safety functions can be bypassed outside the bounds of acceptable and authorized limits, which ensure the safety of the plant is not reduced.

Since $N$ Reactor is not vulnerable to an autocatalytic power excursion accident like that at Chernobyl, risks from other types of accidents have been considered:

- $\quad \mathrm{N}$ Reactor has been subjected to a thorough safety analysis (NUSAR) which covers even worst case accidents.

- An ongoing probabilistic risk assessment (PRA) by an independent government laboratory has revealed no unexpected accident sequences or initiators.

- Preventing several hypothetical accident sequences rests on ensuring the integrity of the coolant-carrying process tubes. Protection from multiple tube failures results because:

- As-procured process tubes were conservatively designed.

- Effects of graphite distortion and seismic events were analyzed to show that design criteria are still satisfied. 
- Process tube monitoring programs, recently enhanced, provide assurance that degradation will be detected before its limiting condition.

- Design margins are defined to ensure that failure of a single tube will not result in failure propagation.

There are provisions for dealing with a severe accident emergency at N Reactor:

- The reactor is located on a relatively remote site with over 35 miles to a major population center (compared to 3 miles at Chernobyl).

- Formal plans are in place, and continualiy practiced in accordance with DOE requirements, for handling emergencies, evacuations and recovery operations in case of severe accidents.

- Onsite fire fighters and emergency crews are trained to deal with fires in radiation zones and radioactive materials.

This lessons learned review was organized to cover Issues identified by NRC staff in their assessment of Chernobyl implications for reactor 1 icensing in this country. Although major causes of the Chernobyl accident do not offer lessons directly applicable to $\mathrm{N}$ Reactor, it is appropriate to recognize the vulnerability that comes from complacency. Thus, the Chernobyl experience served as a stimulus and the NRC Issues provided a framework to pursue questions intended to clarify strengths or weaknesses and highlight possibilities for further improvements in $N$ Reactor safety posture. An extensive Safety Enhancement Program is proceeding that includes upgrades relevant to the NRC Issues. Some recommendations were developed that point out further possibilities for safety improvements or emphasis. The more significant recommendations address:

- Additional attention to several aspects of approvals for changes in limits and for tests

- Addition of some refinements to planned enhancement of training covering response to accidents

- Reinforcement of ongoing evaluation activities to improve confidence in the validity of identified safety margins. 


\section{COMPARISON BETWEEN N REACTOR AND CHERNOBYL}

The safety of $\mathrm{N}$ Reactor has been elevated to a public issue because of some design similarities to the Soviet RBMK reactor at Chernobyl. While the two reactors have some common features, they al so have many different features. In addition, the reactor characteristics associated with the common features are very different. The purpose of Sections A and B is to describe the major features of the two reactors and show how they differ. The discussion covers both design features and some important operations features.

Table II.1 presents a summary comparison of some significant design and safety features between $N$ Reactor and the RBMK. Differences in the design basis for a number of safety features are identified, with expanded descriptions provided in Sections $A$ and $B$.

The importance of differences in the design and operating features between $\mathrm{N}$ Reactor and the Chernobyl plant is demonstrated in Section $\mathrm{C}$. The Chernobyl accident sequence is described and the effect of the plant features involved in the accident are discussed. The $N$ Reactor features that preclude a similar accident are highlighted.

\section{A. DESIGN FEATURES COMPARISON}

$\mathrm{N}$ Reactor and the RBMK are both graphite-moderated, pressure tube reactors. Outside the two common features of graphite moderator and individual pressure tubes (fuel channels) the reactors have few common design features. Major design features are compared in the following discussion.

\section{Moderator}

Both reactors use graphite as the neutron moderator. However, the moderator/ fuel ratios are different, resulting in major differences in coolant void reactivity coefficient. In an RBMK, the moderator consists of graphite blocks $250 \mathrm{~mm}$ (9.8 inch) in cross section and $600 \mathrm{~mm}$ (23.6 inch) in Tength. Each block has a cylindrical hole along its axis for the fuel channels. The blocks are stacked tightly together. In $\mathrm{N}$ Reactor, the graphite blocks are stacked in a "Lincoln Log" fashion. Tube blocks run parallel to the fuel channels and filler blocks run perpendicular to them. Gaps between the blocks reduce the effective graphite density. These spaces also allow for passage of helium cooling gas and steam venting in the event of a tube rupture. 
TABLE II.1. Summary of Key Similarities and Differences Between N Reactor and Chernoby

Basic Characteristic

\begin{tabular}{lll}
\hline Feature & Chernobyl & N Reactor \\
$\begin{array}{l}\text { Void } \\
\text { Coefficient }\end{array}$ & Positive & Negative \\
$\begin{array}{l}\text { Shutdown } \\
\text { System }\end{array}$ & One system & Two systems \\
$\begin{array}{l}\text { Rate of } \\
\text { Shutdown }\end{array}$ & $\begin{array}{l}>15 \text { second } \\
\text { insertion }\end{array}$ & $\begin{array}{l}<3 \text { second } \\
\text { insertion }\end{array}$
\end{tabular}

Control Rod Design

Graphite follower attached to end of rod

Testing and Maintenance of Safety Circuits

Performed at
power from
control room

\section{Design}

Basis

Accident

Pipe Break Protection Assumption

$$
\begin{aligned}
& \text { Large pipe } \\
& \text { breaks plus } \\
& \text { limited } \\
& \text { transients }
\end{aligned}
$$

Rely on "leak Assume maximum before break" to exclude many break locations

Fuel Design $\begin{aligned} & \text { Oxide fuel } \\ & \text { in pins }\end{aligned}$

No graphite follower

Performed at shutdown from control room

\section{All pipe breaks plus all credible transients \\ Limited design
basis for safety
systems
performance} pipe break at al1 locations

Metallic uranium bonded to zirconium cladding
*ATWS = Anticipated Transient Without Scram $* *$ LOCA $=$ Loss of Cooling Accident

\section{Safety systems}

No protection for many break locations

\begin{tabular}{|c|c|}
\hline Chernobyl & N Reactor \\
\hline Unstable & $\begin{array}{l}\text { Inherently } \\
\text { Stable }\end{array}$ \\
\hline $\begin{array}{l}\text { Higher ATWS* } \\
\text { potential }\end{array}$ & $\begin{array}{l}\text { Very low ATWS* } \\
\text { potential }\end{array}$ \\
\hline $\begin{array}{l}\text { Speed of react- } \\
\text { ivity control } \\
\text { dependent on } \\
\text { partial rod } \\
\text { insertion }\end{array}$ & $\begin{array}{l}\text { Speed of control } \\
\text { independent of } \\
\text { rod position }\end{array}$ \\
\hline
\end{tabular}

Cladding fails rapidly on cooling interuption (LOCA**)
Initial reactivity Rod insertion increase for rod insertion from a)ways decreases reactivity routinely partially bypass at power bypassed at power is prohibited

Safety system performance designed for full range of credible events

Protection for all break sizes and locations

Fuel heatup to failure takes much longer time 
TABLE II.1 (Continued)

Basic Characteristic

\begin{tabular}{|c|c|c|}
\hline Feature & Chernobyl & N Reactor \\
\hline $\begin{array}{l}\text { Pressure } \\
\text { Tube } \\
\text { Orientation }\end{array}$ & Vertical & Horizontal \\
\hline $\begin{array}{l}\text { Containment } \\
\text { Philosophy }\end{array}$ & $\begin{array}{l}\text { Segregated, } \\
\text { does not } \\
\text { include } \\
\text { reactor and } \\
\text { some piping }\end{array}$ & $\begin{array}{l}\text { large volume } \\
\text { enclosing reac } \\
\text { and coolant } \\
\text { system }\end{array}$ \\
\hline $\begin{array}{l}\text { Containment } \\
\text { Design } \\
\text { Basis }\end{array}$ & $\begin{array}{l}\text { Varies, } \\
\text { depending on } \\
\text { energy input }\end{array}$ & $\begin{array}{l}\text { Low-pressure } \\
\text { structure }\end{array}$ \\
\hline $\begin{array}{l}\text { Fission } \\
\text { Product } \\
\text { Retention } \\
\text { Mechanisms }\end{array}$ & $\begin{array}{l}\text { Suppression } \\
\text { pool }\end{array}$ & $\begin{array}{l}\text { Confinement- } \\
\text { filtered Vent }\end{array}$ \\
\hline $\begin{array}{l}\text { Siting } \\
\text { Emergency } \\
\text { Action Basis }\end{array}$ & $\begin{array}{l}\text { Near popula- } \\
\text { tion centers }\end{array}$ & Remote \\
\hline
\end{tabular}

Influence

\begin{tabular}{ll}
\hline Chernobyl & N Reactor \\
$\begin{array}{l}\text { Disruption creates } \\
\text { "chimney" through } \\
\text { core }\end{array}$ & $\begin{array}{l}\text { static graphite } \\
\text { "crucible" }\end{array}$
\end{tabular}

No containment Effective confinement for all accidents accidents
Requires know-
ledge of energy
release

No retention except for large pipe break events

Immediate offsite actions required
Effective for all energy releases within design basis

Permanent retention for all events***

No immediate, major offsite actions required

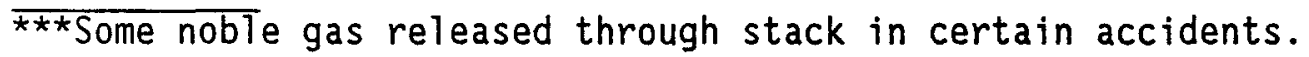


The ratio of graphite moderator to uranium fuel is larger in an RBMK than in $\mathrm{N}$ Reactor. This results in an RBMK having optimum neutron moderation from the graphite alone. Because of this, the cooling water (which can provide neutron moderation) is not needed for moderation and, thus, has a negative effect on the neutron utilization in the core. The water absorbs neutrons and acts as a neutron sink. Therefore, when water is removed from the fuel tubes by boiling during normal operation or leakage, the neutron absorbtion decreases resulting in a reactivity (power) increase. This effect is referred to as a positive coolant void coefficient of reactivity, or simply positive void coefficient. The magnitude of the reactivity increase is a function of the fuel residence time, fuel enrichment, coolant void fraction, and the number of control rods present in the core.

In $N$ Reactor the cooling water is a vital contributor to neutron moderation. The graphite alone does not provide for optimum neutron moderation. The coolant, therefore, provides a positive effect on neutron utilization. The positive effect of added moderation more than offsets the negative effect of neutron absorbtion. If water were removed from a fuel channel, the loss of moderation would cause the reactivity (power) to decrease. $N$ Reactor, therefore, has an inherent negative coolant void coefficient. There are no operating conditions that cause $\mathrm{N}$ Reactor to have a positive coolant void effect.

\section{Coolant}

Both reactors use light water as the coolant. However, in an RBMK the coolant begins to boil about one-third of the way up the fuel channel and exits with a void fraction of nearly $80 \%$. For this reason the reactor is referred to as a boiling water reactor. $N$ Reactor coolant does not boil. In this respect it is more like a pressurized water reactor. Both reactors operate at approximately the same coolant temperatures. N Reactor pressure is slightly higher to prevent boiling.

\section{Fuel Channels}

Both reactors use individual zirconium alloy tubes to contain the fuel within the reactor core. The RBMK tubes are oriented vertically and have a $9 \mathrm{~cm}$ (3.5 inch) diameter and a wall thickness of $0.4 \mathrm{~cm}(0.16$ inch). N Reactor tubes are oriented horizontally and are $8.2 \mathrm{~cm}(3.2 \mathrm{inch})$ in diameter with a wall thickness of $0.7 \mathrm{~cm}(0.28$ inch). There are 1661 fuel channels in an RBMK and 1003 fuel channels in $\mathrm{N}$ Reactor. 
4. Fuel

The RBMK uses uranium-oxide fuel arranged in two rings of zirconium-clad rods; six rods are in the inner ring and 12 rods are in the outer ring. Each fuel assembly consists of two $3.5-\mathrm{m}$ (11.5-feet) long sections joined end-toend. The uranium enrichment is $2 \mathrm{wt} \% \mathrm{U}-235$.

$N$ Reactor uses uranium metal fuel arranged in a tube-in-tube geometry. The fuel is clad with zirconium alloy by means of a coextrusion process that produces a mechanical bond between the cladding and the fuel. Seventeen elements approximately $0.6 \mathrm{~m}$ (23.6 inch) in length are loaded into each fuel channel. The core loading consists of fuel with two enrichments, 0.95 wt\% $\mathrm{U}-235$ and $1.25 \mathrm{wt} \% \mathrm{U}-235$.

\section{Control and Shutdown System}

Reactivity control for power control and shutdown in an RBMK is accomplished by 211 movable absorber rods. Additional reactivity control at the beginning of life is accomplished by placing fixed absorbers in approximately 300 of the fuel channels. As the initial reactivity decreases because of fuel burnup, the fixed absorbers are replaced with fuel. During equilibrium operation, about two or three years after initial startup, no fixed absorbers are required. At the time of the Chernobyl accident there was only one fixed absorber in place.

A11 but 24 of the 211 control rods are inserted from the top of the core. The other 24 are raised into the bottom of the core to assist in axial power control. When a control rod is pulled upward out of the core, a graphite follower is pulled along to displace the rod channel cooling water. Since the cooling water acts as a neutron absorber, the graphite follower reduces this unwanted loss of neutrons. If the control rod is pulled to its upper limit, the $5-\mathrm{m}(16.4-\mathrm{feet})$ long graphite follower is axially centered in the $7-m$ (23-feet) tall core which leaves $1 \mathrm{~m}(39.4 \mathrm{inch})$ of the rod channel at the bottom to be completely filled with water. When a fully withdrawn rod is inserted, the graphite follower initially displaces this water in the bottom $1 \mathrm{~m}$ (39.4 inch) of the core resulting in a local power increase during the first part of the insertion. In effect, the scram initially produces a reactivity increase, which is then followed by an overriding reduction in reactivity. This characteristic was likely a major contributor to the severity of the Chernobyl accident.

Movement of the RBMK control rods is provided by a pulley and cable system. All rod insertion requires the unwinding of the cable from the pulley. As a result, the rods require approximately 20 seconds to fully insert during a scram.

N Reactor has 84 horizontal control rods divided into two separate banks that enter from opposite sides of the reactor. That is, the rod motion is horizontal and perpendicular to the orientation of the fuel channels. The 
rods move in channels within the graphite moderator. These channels are open to the graphite stack cooling gas. The rod cooling water is an integral part of the rod itself; therefore, there is no need for a rod follower. Under no conditions can the insertion of an $N$ Reactor control rod cause a reactivity increase.

A hydraulic system is used for movement of $N$ Reactor control rods. Following a scram signal, rods are fully inserted within two seconds from their fully withdrawn position. Energy for this rapid insertion is provided by compressed-nitrogen hydraulic accumulators, one for each rod.

In addition to the control rod system, $N$ Reactor has a fast response backup shutdown safety system. Vertical channels through the graphite moderator can be filled with boron-graphite balls to accomplish reactor shutdown. This system is activated if the rods fail to insert in the required time, if power is not rapidly reduced after scram or if the reactor is not rendered and maintained subcritical after scram. The boron ball safety system al so would insert automatically from a seismic signal or a signal to activate the Emergency Core Cooling System (ECCS). The boron ball backup system performs its functions automatically without a need for operator action; however, the operator can activate the system (pushbutton). Insertion of either rods or boron balls will shut the reactor down and hold it down indefinitely.

\section{Reactor Enclosure}

An RBMK core is enclosed within a $1.6-\mathrm{cm}(0.6-$ inch) thick cylindrical steel tank bounded on the top and bottom by $1-m$ (39.4-inch) thick steel and concrete shields. The zirconium alloy tube fuel channels and control rod channels are welded to the upper shield. Pressure relief for the reactor space is designed for the rupture of a single fuel channel tube. Rupture of more than one channel overpressurizes the enclosure. If several channels were to rupture, the overpressure would cause the upper shield to lift up. Since the fuel channels and rod channels are welded to the upper shield, any upward movement ruptures all the fuel channels and causes the control rods to be lifted out of the core. This characteristic was a major contributor to the severity of the Chernobyl accident.

The $N$ Reactor core enclosure consists of concrete biological shields on the top and both sides. These shields are connected. The enclosure at the front and rear is not attached to the top and side shields and is designed to move as the Zircaloy fuel channel tube expands and contracts. The pressure relief system is designed to accommodate the rupture at power of a single fueled pressure tube. Analyses show that single tube rupture will not propagate to fail other tubes. Surveillance programs ensure continued protection from multiple process tube ruptures in the core. 
The ECCS on the RBMK is designed to cool the reactor core in the event of an inlet pipe break, and must operate without availability of normal electric power. There are separate coolant inlet systems for each half of the reactor; the ECCS is designed to initially cool the damaged half of the reactor. The system is brought into operation by fast-acting electric gate valves with electrical power for both valves and pumps being supplied by batteries. Water is obtained from two separate banks of pressurized storage tanks for the initial 100 seconds. A third leg uses water from an electric feed pump run from power available from the turbine generator (TG) coast down. It was this feature that was under test when the Chernobyl accident occurred. For long-term afterheat removal, battery-driven cooling pumps supply water to both the damaged and undamaged halves of the reactor. Water is recirculated from the blowdown suppression pools beneath the reactor vessel.

Diesel-motor driven pumps provide the pressure to deliver water to the core in the $N$ Reactor ECCS. When activated, the system draws down water from storage tanks for a once-through flow. If that supply is exhausted, a separate set of diesel pumps brings water to the system from the Columbia River. The initial stage of ECCS activation consists of opening valves and using compressed air activators to allow blow-down of the pressurized coolant. Because of the slow rate of heat-up in $\mathrm{N}$ Reactor and the margins to fuel damage from undercooling, the reflood system does not have to be fast-acting (i.e., within seconds). In addition to the main ECCS, there is a second backup cooling system in $N$ Reactor. The Graphite and Shield Cooling System (GSCS) is a separate system of tubing that traverses the graphite stack to cool the graphite. Even for an assumed case where a LOCA occurred and the ECCS malfunctioned, the GSCS has sufficient cooling capacity to limit meltdown and stabilize a degraded core scenario. The GSCS is supplied with water by a set of diesel-driven pumps separate from the ECCS pumps. Like the ECCS, an unlimited supply of water is available from the river.

\section{Containment/Confinement}

There is no containment or confinement enclosing the entire RBMK reactor. Mitigation of primary coolant system ruptures is accomplished by enclosing only certain portions of the primary cooling system inside pressure boundaries. The compartments enclosing the primary pump inlet and outlet headers are designed to accommodate the rupture of a single $30-\mathrm{cm}$ (12-inch) diameter pipe. The piping from the outlet header to the fuel channel inlets is also enclosed in a pressure-tight compartment. All the remaining piping (fuel channels, channel outlets, steam drums, and steam lines) are outside any pressure boundary. The coolant circuit ruptures that occurred during the Chernobyl accident occurred in the piping outside the pressure-tight compartments. 
$N$ Reactor has a vented confinement system that encloses the entire reactor and primary cooling system. Its design is based on early venting of the noncontaminated steam resulting from any break (or multiple breaks) of the primary coolant piping. Following the steam venting, the vents are closed and any further venting is through filters designed to remove radioactive materials. A water spray activates automatically as part of this system to provide cooling/condensation of the released steam and to remove radioactive materials from the atmosphere. This system is designed to accommodate the sudden double-ended rupture of the largest primary system pipe or manifold [e.g., a 66-cm (26-inch) diameter outlet manifold].

B. OPERATING FEATURES COMPARISON

In addition to differences in physical plant design, the RBMK and $\mathrm{N}$ Reactor differ in their operating characteristics and procedures. The design gives the reactors different response characteristics. Administrative controls result in a different operating philosophy as well as operator control.

\section{Operating Characteristics}

As stated earlier, an RBMK operates with a positive coolant void coefficient in the low-power range $(<20 \%)$. The reactor's coolant undergoes large changes in void content during normal operation. During the early development of the RBMK-type reactor, severe problems were encountered in maintaining the desired spatial power distribution because of the void coefficient. Subsequent reactors were modified to have lower graphite density, higher fuel enrichment, and a computer-assisted control system to allow for stable operation. Even with these changes, control rod removal was restricted to prohibit removal of al1 rods during operation. The Soviets state that one of their most important rules is that the inserted rod worth must never be less than 15 equivalent rods (this is accomplished by having roughly a hundred rods partially inserted at all times). The reason for this restriction is that the magnitude of the positive void coefficient becomes larger as the inserted rod worth is reduced. Normally the Soviet reactors operate with an inserted rod worth of 30 equivalent rods. No alarms or automatic actions exist to indicate that the inserted rod worth is below the minimum value.

$N$ Reactor, with its negative coolant void coefficient, has a stable spatial power distribution. Spatial power distribution control is achieved by manual control alone. Stability is not affected by the amount of inserted rod worth.

For an RBMK, refueling is usually accomplished with the reactor on-line. With the reactor operating at full power, especially designed equipment is used to open an individual flow tube, extract the burned fuel from that tube, and insert a replacement fuel assembly. The ends of the flow tubes giving 
access to the reactor core for this operation, along with the associated equipment, are in the reactor building area outside of any confinement structures.

Refueling at $N$ Reactor can only be accomplished with the reactor shut down. Burned fuel is pushed out one end of the process tube where it falls into a water-filled spent fuel basin. Spent fuel is discharged inside the closed confinement structure.

\section{Operator Training}

The Soviets state that their operators are well-educated, highly trained individuals. In fact, following the Three Mile Island (TMI) accident, the Soviets concluded there was no need to make changes in their operations since their operators were better trained than their U.S. counterparts. The exact nature of the Soviet training methods is not known. However, we do know there are no ful1-scale simulators for the RBMK. The Soviets have emphasized the fact that operator actions played a major role in the accident.

$\mathrm{N}$ Reactor operator training involves formal classroom instruction, use of a full-scale plant simulator, and a period of closely supervised on-the-job experience. A full-time training organization is in place to train new operators and to administer a program for scheduled, periodic recertification of all reactor operator personnel.

\section{Test Control}

A major factor in the Chernobyl accident was the failure to maintain control over the conduct of a special test. The test was conducted without all the proper approvals, control of the reactor was essentially turned over to an electrical engineer who knew little about plant operations, and the operators allowed the test to continue far outside the safe operating limits of the reactor. We do not know the details of the Soviet administration and control of special tests.

Tests in $N$ Reactor are governed by a set of formal, documented requirements. Test descriptions and procedures require extensive review and approval before any test can be conducted. The review includes operations, nuclear and plant safety, and engineering. Tests are controlled by written procedures, and are directed by two responsible "Test Directors": an Operations Test Director and a Technical Test Director. Agreement of both is required before proceeding with the steps of the test procedure. The Operations Test Director and Operations shift management have the authority and responsibility to unilaterally order test cessation or reactor shutdown if known, safe conditions cannot be ensured. Both test directors and a Safety manager must approve minor changes and the original review cycle is required for major 
changes. Any test that requires temporary modification of a technical specification or results in an "unreviewed safety question" must have formal approval of the DOE.

\section{Operations Control}

The Chernobyl accident sequence is characterized by a number of operator actions that resulted in disabling emergency protection systems, disconnecting scram signals and operating outside known plant safety margins. The operators apparently removed or disconnected safety functions without approval from higher level plant management.

$\mathrm{N}$ Reactor operators function within the framework of a system of procedures and limits identified as Process Standards. Compliance is required during operation, unless the Process Standard limits are superseded by approved test conditions or changed according to a formal procedure. All tests or changes to limits must fall within the approved Technical Specifications; changes to Technical Specifications require review and approval of DOE. N Reactor operators have the ability to bypass some safety circuits from the control room, but controls must always comply with approved Technical Specifications. Procedures for use of bypasses limit use of this feature to periods of reactor shutdown (control rods and/or balls already inserted).

\section{CHERNOBYL ACCIDENT DESCRIPTION}

The following section contains an accident summary description that was extracted directly from DOE/NE-0076, Appendix C. It indicates the operator actions and the design features of the Chernobyl plant that were contributing factors to cause the accident. The features of $N$ Reactor that would have protected it from the accident are also identified.

\section{General Description of the Test That Led to the Accident}

The accident at Chernobyl occurred during a planned test that was to be conducted at power of $\sim 700$ MWt as Unit No. 4 was being taken out of service for maintenance. In the test, it was desired to verify the ability of a TG to continue to provide electric power for internal operation of ECCS equipment, such as feedwater pumps, during a turbine rundown. This is interpreted to mean during loss of offsite power, where continuous power to vital safety equipment is needed until the emergency diesel generators become operational.

At $N$ Reactor, emergency facilities are provided to accommodate a total and instantaneous loss of $A C$ power. Therefore, tests of this type are not required and have not been performed. 
This test repeated a similar test conducted at Chernobyl-4 in 1985 during which the busbar voltage dropped much faster than the turbine rundown. In the present test, an electrical engineer was directing testing of a special generator field regulator designed to maintain higher busbar voltage for a prolonged time.

At $N$ Reactor, two test directors are required: one from Operations and one representing the sponsor, and both are responsible for safely conducting the test. As a test proceeds from step to step, both directors must agree to proceed, either can terminate the test, and both must agree to minor changes in the test procedures; major changes require re-analysis, additional reviews and reapproval.

The reactor power operation was needed only to provide steam for initial turbine operation. The TG was being loaded primarily by four primary coolant pumps of the reactor; four additional pumps were being powered from outside sources so that even upon complete turbine rundown there would still be substantial coolant flow through the reactor for heat removal.

The test procedure prescribed that the ECCS be disengaged for the duration of the test.

In contrast, at $N$ Reactor it is mandatory that the ECCS be operable (i.e., automatic activation armed and the system ready to operate) whenever the reactor is at power or undergoing startup.

The procedure also prescribed that one of the two TGs powered by Unit No. 4 be taken out of service as an initial condition. After a delay of about nine hours, the test was initiated by shutting down steam flow to the remaining TG, initiating the rundown. According to the Soviet report, shutdown of the second $T G$ should have automatically scrammed the reactor, which would have been appropriate since neither the reactor power nor continued steam generation should have played any further role in this test. However, this particular reactor scram signal, actuated by shutoff of steam flow to both TGs, had been blocked during the previous day "to have the possibility of repeating the test, if the first attempt proved unsuccessfur." (They were concerned about xenon buildup.) Thus, the Soviet test was being conducted with the reactor continualiy generating power rather than automatically scrammed as planned.

At $N$ Reactor, a change in a safety system cannot be made without a complete review and approval of the entire test procedure. This includes a safety analysis of the proposed change. This process would have identified the potential hazard and the proposed change would have been disapproved.

At this point, in effect, three of the Chernobyl reactor's safety systems had been rendered inoperative while performing a safety test at power. Specifically, the ECCS had been disengaged and the automatic scram of the TG upon 
loss of steam flow had been bypassed, and a scram from steam drum thermal and level upset had been disabled.

In contrast, at $\mathbf{N}$ Reactor, safety systems are tested, maintained and qual ified during shutdown and there is no need to bypass a safety system at power. Such bypasses are prohibited.

The reactor was manually scrammed 36 seconds $(1: 23: 40)$ 1ater when the operators observed the increasing power. By that time scram was too late in the RBMK, the damaging power excursion was under way, fed by the positive reactivity insertion due to the increasing coolant boiling and the initial positive reactivity feedback of the rod scram.

\section{Conditions Contributing to the Accident}

The accident might still have been avoided, or considerably less severe, except for other circumstances. These circumstances involved a sequence of operator mistakes combined with a number of sensitive design features of the RBMK. Specifically, the local automatic power regulating rods (LAR) had been disengaged according to standard operating procedure for low-power operation, and hence were not available to counteract the voiding reactivity insertion. The global automatic power regulating rods (AR) were operational and were automatically inserted by the plant diagnostics and computer control system, partially compensating for the power rise but apparently without sufficient worth. Other absorber rods had been completely withdrawn previousiy to counteract xenon buildup and overcooling effects. When finally scrammed, these rods were too far out of the core to be of immediate worth and moved at too slow insertion speed $(0.4$ meters per second; about 20 seconds full insertion time) to terminate the overpower excursion.

The operating procedures on all RBMK units require a certain control reactivity margin expressed as an effective number of control rods which must be in the core at all times. The normal requirement is 30 rods while the number properly positioned at this point in the test was set to 8 . This serious violation of an operating procedure specifying the reactivity control margin did not prevent Chernobyl's reactor operators from continuing the test. In contrast, the worth of the $N$ Reactor control rod system does not depend upon compliance with any administrative procedure. Moreover, the rod insertion speed is considerably faster with $75 \%$ of the rod inserted in less than 1.5 seconds. Both written requirements and training direct that deviation from an operating or test procedure must be reviewed and approved, and any significant deviation is sufficient to abort the test.

Because of the particular design of the RBMK control rod assemblies when the absorbers were fully withdrawn, the control assembly duct contained 5 meters of graphite displacer centrally located in the 7 -meter $(23$-feet) core with 1 meter $(39.4$ inch) of water above and below the graphite at the axial extremes 
of the core. In this configuration, it is calculated that the initial scram effect was not negative but positive reactivity insertion because of displacement of water, particularly at the bottom of the core. This circumstarce probably caused a significant power shift to the bottom of the reactor.

The design of the $N$ Reactor control rods ensures that negative reactivity always results from rod insertion. Moreover, an independent and diverse shutdown system is always available. This system automatically drops boron-carbide neutron absorber balls.

Additionally, the reactor was at very low power (7\%) and very high coolant flow $(>100 \%)$. Hence, the initial steam void in the core was exceedingly sma 17 , about $2 \%$ average. The Soviet report emphasizes that in this condition a small change in power causes the volumetric steam content to increase "many times more sharply than at nominal power." It is also believed that the void coefficient of reactivity is itself a function of void fraction, being larger for smaller void condition. These two factors would combine to cause the void reactivity insertion to be particularly severe under the conditions during which the test was run.

The coolant void coefficient in the RBMK units is positive, which introduces the autocatalytic potential from an increase in power which will increase the coolant void which will further increase the power, etc. In contrast, at $N$ Reactor the coolant temperature coefficient is negative, ensuring that any increase in power will increase the coolant temperature which will automatically decrease the power. The $N$ Reactor coolant does not boil. If boiling should occur, the result would be a negative change in reactivity owing to the negative void coefficient. All other prompt reactivity coefficients also add negative reactivity as temperature increases.

Immediately before the test, the operator "sharply reduced the feedwater flowrate." Hence, the temperature of the water to the main coolant pumps and to the core inlet was increasing since suction was now primarily from the steam separator drum. Increasing water temperature at the core inlet may have exacerbated the steam generation in the core.

In summary, the circumstances leading to the accident were as follows: (1) the reactor was operating (though it should have been scrammed from the onset); (2) the coolant flow rate was decreasing leading to additional steam generation in the core; (3) the coolant inlet temperature was increasing, leading to more rapid steam generation in the core; (4) the initially overcooled core with close to zero steam content was in a particularly vulnerable state with regard to void-related reactivity insertion; (5) the automatic power regulating system was incapable of counteracting the void reactivity insertion; (6) the rods available for scram were located fully out of the reactor core in a region of low initial worth; and (7) the scram itself is calculated to have caused a sizeable reactivity insertion initially. 
WHC-SP-0257

3.

Transient Overpower Excursion

Under the conditions described, a net positive reactivity caused by increasing coolant boiling in the core resulted in a power rise. At first the rate of power rise was slow. At 1:23:40 the reactor was manually scrammed, but without the desired shutdown effect. At 1:23:43 the power was reported to have exceeded $520 \mathrm{MW}$ (up from $200 \mathrm{MW}$ at the beginning of the test), and the "runaway period came to be much less than 20 seconds." Actually the reactor was already experiencing a prompt critical power excursion at that time. It is stated that "only the (fuel) Doppler effect partially compensated for the reactivity introduced at this time." The power transient calculated by the Soviets had a peak power of $350,000 \mathrm{MW}(110 \times$ full power) and a full width at half maximum (FWHM) of 0.8 seconds. The Soviets indicate that the energy release in the fuel "exceeded $300 \mathrm{cal} / \mathrm{g} . "$

The effect of the power burst is described in the Soviet report as follows: "[The power rise] led to an intensive steam formation and then to nucleate boiling, overheating of the fuel, melting of the fuel, a rapid surge of coolant boiling with particles of destroyed fuel entering the coolant, a rapid and abrupt increase of pressure in the fuel channels, destruction of the fuel channels, and finally an explosion which destroyed the reactor and part of the building and released radioactive fission products to the environment."

A catastrophic autocatalytic power excursion such as this cannot occur at $N$ Reactor because of the strong negative power coefficient. The presence of two independent nuclear control shutdown systems makes it unlikely that any excursion that could occur would damage the fue1. This leaves considerable margin to core disruption and any possibility for release of fission products to confinement.

4. Consequences of the Overpower Transient

The above description suggests that fuel-coolant thermal interactions (FCIs) occurred from the sudden mixing of hot (including molten) $\mathrm{UO}_{2}$ fuel and coolant in the channels, and that the subsequent pressurizations caused channels to rupture. (The plausibility of this was subsequently confirmed through the application of Argonne National Laboratory accident analysis codes.) Rupturing the channels would initiate blowdown of steam and flashing water from about $6.5 \mathrm{MPa}$ pressure to the surrounding volume(s). The Soviet's report is silent on the suspected locations of ruptures. There are thought to be four principal locations:

- Upward slug expulsion from the pressurization zone has been shown to be capable of breaching the top end cap of the operating channel at the refueling machine attachment, initiating upward blowdown and fuel dispersal into the uncontained region immediately below the removable refueling floor slabs. 
- The zirconium-to-steel weld joints immediately above and below the active fuel zone of the core are thought to be weak points; failures of the piping at either or both of these locations would cause steam blowdown into the region of graphite blocks in the sealed reactor space.

- The zirconium-alloy pressure tube is likely to fail locally at the region of the pressurization event due both to the overpressure itself and to thermal effects of fuel impingement on the pressure tube wall. This failure location would cause steam blowdown into the central zone of graphite blocks in the sealed reactor space.

- It is also possible that shock pressures and water-hammer pressures propagated upstream as a result of the pressurization events in the operating channels and damaged piping at the inlet side of the reactor; blowdown of steam and flashing water would enter the containment cell (65 psig) designed to vent to the pressure suppression pool.

Any or all of these types of ruptures could have occurred from the initial fuel failure events. The ruptures of the top end caps would have caused the immediate blowdown and discharge of fuel debris upward into the refuel ing building and possibly directly into the atmosphere. Multiple tube ruptures into the reactor space would quickly overpressurize this region since its overpressure relief protection is sized for failure of only one channel. Upon overpressurization this region would fail structurally, as is known to have occurred. Some of the graphite blocks were ejected, and the reactor core was opened to the atmosphere.

It is reported that two explosions were heard, "One after another, " and that "hot fragments and sparks" flew up above the plant, described elsewhere in the report as "fireworks of flying hot and glowing fragments." The mechanism for this dispersal may have involved the upward-directed channel ruptures at their tops, the overpressurization failure of the reactor vault and subsequent blowdown of that region, or a subsequent explosion of some other origin. There are statements in various parts of the report attesting that fuel debris was ejected into the atmosphere; e.g., "As a result of explosions in the reactor an ejection of core fragments heated to a high temperature... (occurred)." The report also speculates that a chemical explosion could have occurred "after unsealing of the reactor space." These statements are not necessarily contradictory; they indicate uncertainties in the actual sequence and consequences of multiple events. However, observations made by Russian engineers using video cameras on robots indicated no evidence of a hydrogen burn.

It is important to note that there is no specific evidence that either a hydrogen explosion or graphite fire was a contributor to the reactor disruption up to this point. 
5. Chernobyl Plant Features that Exacerbated Accident Consequences

Although the Soviets place heavy blame for the accident on the individuals who planned and carried out the TG rundown test and on the reactor operators rather than on equipment failures or design shortcomings, it is clear that features of the RBMK reactor design contributed to the severity of the accident.

a. The scram rod insertion speed is much too slow to provide adequate protection against emergency situations such as arose during the accident. The Soviet approach is that large numbers of rods compensated for their slow rate of insertion. The insertion rate is stated to be 0.4 meters ( 15.8 inch) per second, and since the total core height is 7 meters ( 22.9 feet), it takes about 18 seconds for complete scram rod insertion.

In contrast, the comparable scram time for the control rod system in $N$ Reactor is less than three seconds. In addition, $N$ Reactor has a completely independent ball drop system that has sufficient insertion speed to prevent fuel damage even if the rod system failed to respond.

b. There was no positive stop on the absorber rods to limit their withdrawal. The rods were so far out of the core that they did not immediately insert negative reactivity as depended upon when the reactor was scrammed. To the contrary, the rod design and initial position caused a "positive scram," i.e., there was a major positive reactivity insertion upon scram, rather than shutdown.

The "positive scram" appears to be unique to the RBMK design and to the particular state of the reactor; there is no positive scram effect in $N$ Reactor.

c. Many parts of the reactor piping system passed through areas where there was no containment whatsoever. This includes the top sections of the operating channels, steamwater lines, steam line piping, and parts of the feedwater and return 1 ine piping. It is indicated that fuel debris was released directly to the atmosphere at Chernobyl-4 as a result of pipe ruptures and blowdown into uncontained regions.

In contrast, $N$ Reactor has a large volume confinement system that totally encloses the reactor and the primary coolant system. Release of coolant, fuel or core debris from the primary system would be limited to the confinement structure.

d. The zirconium-to-steel transition welds are thought to be weak points in the RBMK piping system, although it is uncertain whether this played any role during the accident. The welds have a heatup rating limited to 
$15^{\circ} \mathrm{C} /$ hour which may have been exceeded during the accident. Since rupture of the piping at the welds would cause blowdown into the sealed reactor space, the welds are a potential cause of failing the vault during the accident involving multiple ruptures.

There are no comparable weld joints within the N Reactor shield enclosure. Previous analyses indicate that an accident caused by a guillotine rupture of a process tube in N Reactor would terminate without propagation. These analyses have been reviewed and updated and surveillance of process tubes has been further emphasized to ensure that multiple tube failures will not result from any plausible initiating event.

e. With the primary cooling system damaged in an RBMK unit, there is no mechanism for removing the heat generated by either fission product decay, metal-water reactions, or graphite oxidation.

N Reactor has a separate system (GSCS) that cools the graphite moderator and which could stabilize and cool the core within a few hours after total cooling loss. This heat removal mechanism would have several very important benefits: it would limit the amount of fuel that would heat up and fail to about one-third the loading; it would reduce (temperature dependent) rates of metal-water reactions and graphite oxidation so that they would not significantly increase the consequences of the accident; and it would maintain damaged fuel inside the pressure tubes. 


\section{LESSONS LEARNED REVIEW PROCESS}

Since the accident at Chernobyl on April 26, 1986, the availability of detailed information has continually increased. While much of the early information was directed to those expert groups chartered to compile and interpret it, two recent reports represent a definitive basis for further evaluation and application of Chernobyl data. The report of a DOE team, which studied the Russian RBMK 1000 reactor design and detailed the accident sequence was released in November 1986 as DOE/NE-0076. Another report covering a more extensive range of topics, including emergency management, role of operating personnel, and further assessment of the RBMK against U.S. NRC safety guidelines became available in February 1987, issued by the U.S. NRC as NUREG-1250. These two reports represented the primary technical base supporting the lessons learned review.

The approach to reviewing $N$ Reactor for lessons learned from the Chernobyl accident was based on a structure developed by the U.S. NRC for their review of regulatory implications for the U.S. nuclear industry. NRC technical staff presented to the NRC Commissioners on February 6, 1987, a listing of Issues identified from detailed reviews of Russian documents, International Atomic Energy Agency (IAEA) information, and other available sources. This listing, as shown in Table III.1, was used as the basis for this review. Some modifications were made to the list to customize it for the $\mathrm{N}$ Reactor review.

The following statement represents the "Most Important Lesson" from the Chernobyl accident for the U.S. nuclear program as stated by NRC staff:

"The Chernobyl accident reminds us of the continuing importance of safe design in both concept and motivation of plant management and operating staff to operate in strict compliance with controls; and of backup features of defense in depth against potential accidents.

Although a large nuclear plant accident somewhere in the U.S. is unlikely because of design and operational features, we cannot relax the care and vigilance that have made it so."

Participation in this review included staff from both Westinghouse and UNC. Westinghouse representation on the review panel included WHC, W-Nuclear Technology Services Division and its subsidiary, Fauske and Associates. This review served to meet internal objectives and commitments of UNC to assess Chernobyl lessons learned as a part of their Safety Enhancement Program (SEP).

It should be recognized that the timing of this review activity followed some ten months of intensive scrutiny of $\mathrm{N}$ Reactor since the accident at Chernobyl. Six major reviews have already been reported. In response to the recommendations generated by those activities, UNC and DOE have implemented an SEP that is currently proceeding to extend analyses and incorporate upgrades in both plant and administrative systems. Thus, most of the lessons to be learned 
TABLE III.1. NRC Issues from Chernobyl Lessons Review

I. OPERATIONS (ADMINISTRATIVE CONTROLS)

I.1 Administrative Controls to Ensure that Procedures are Followed, and Procedure Adequacy

I.2 Approval of Tests and Other Unusual Operations

I.3 Bypassing Safety Systems

I.4 Availability of Engineered Safety Features

I.5 Operating Staff Attitudes Toward Safety

I.6 Management Systems

I.7 Accident Management

II. DESIGN

II.1 Reactivity Accidents

II.2 Accidents at Low Power and When Shut Down

II.3 Multiple Units (Not applicable to N Reactor)

II.4 Fires* (Addressed as Issue VI)

II.5 Pressure Tube Integrity

III. CONTAINMENT

III.1 Beyond DBA Capabilities

III.2 Filtered Venting

IV. EMERGENCY PLANNING

IV.1 EPZ** Size

IV.2 Ingestion Pathway Measures

IV.3 Decontamination and Relocation

V. SEVERE ACCIDENT PHENOMENA

V.1 Source Terms

V.2 Steam Explosions

V.3 Combustible Gas

VI. GRAPHITE-MODERATED REACTOR * (FIRES)

$\star \star E P Z=$ Emergency $\mathrm{Pl}$ anning Zone 
from the Chernobyl accident have already influenced the safety activities at $\mathrm{N}$ Reactor. However, none of these previous reviews had the advantage of the comprehensive perspectives now available in the DOE and NRC reports. It was from this base that the inquiry reported here was structured.

To accomplish the inquiry process, the combined Westinghouse-UNC review team met with knowledgeable UNC technical and management staff in two separate review sessions that focused on specific Issues from the NRC 1ist. For each Issue, interpretation of features of the Chernobyl accident led to identification of specific questions or inquiries related to $\mathrm{N}$ Reactor. These specific inquiries were then used to obtain information that could show where considerations from Chernobyl could be applied to better define and improve the safety posture of $\mathrm{N}$ Reactor. A review on March 3 addressed the inquiries related to: II. Design, III. Containment, V. Severe Accident Phenomena, and VI. Graphite-Moderated Reactor (Fires). Issues I. Operations (Administrative Controls) and IV. Emergency Planning were addressed in meetings on March 19 and 20. A tour of the $\mathrm{N}$ Reactor Simulator Training facility was included on March 19. UNC and supporting staff who contributed information and responses to the inquiries are noted in Table III.2. Their contributions are gratefully acknowledged.

\section{TABLE III.2. UNC Staff Contributors to Chernobyl Lessons Learned Review}

March 3 Topics: II. Design, III. Containment, V. Severe Accident Phenomena, and VI. Graphite-Moderated Reactor (Fires)
H. Toffer
W.J. Quapp
Manager, Advanced Technology \& Physics
D.G. Ogden
Manager, Analys is and PRA
J.F. Martin (WHC)
Manager, Severe Core Accident Analys is
G.R. Armstrong (WHC)
Lead Engineer, Accident Analys is Codes
L.D. Muhleste in (WHC)
K.V. Scott
G.L. Smith
Manager, Nuclear Systems Analysis
Manager, Safety Systems Development
Manager, Pressure Tube Technology
L.P. Leach
Manager, Technology
Vice President, Engineering

March 19-20 Topics: I. Operations (Administrative Controls) and

IV. Emergency Planning

R.D. Warner

K.R. Mikkelsen

Manager, Nuclear Safety

W.J. Moffitt

Manager, Process Engineering Subsection

F.H. Galegar

Manager, Operations

Manager, Emergency Planning 
WHC-SP-0257

\section{INQUIRY AND CONCLUSIONS}

The specific inquiries developed in the context of the NRC Issues list (Table III.1) are presented in this section. Information from the Chernobyl events that influenced lines of inquiry is noted. Conclusions are summarized based on the information provided to the Review Team in the activities described in Section III. The Review Team's recommendations are noted in the context of the inquiry that stimulated them. The recommendations pertain mostly to refinements in the $\mathrm{N}$ Reactor safety posture, rather than corrective actions.

MAJOR ISSUE I. OPERATIONS (ADMINISTRATIVE CONTROLS)

Issue I.1 Administrative Controls to Ensure that Procedures are Followed and Procedure Adequacy

Basis from Chernobyl Events

1. Operators performed $\mathrm{i} 1$ legal bypasses (ECCS and safety circuits).

2. Operators deviated from mandatory configurations (the amount of inserted reactivity control was below allowable levels, coolant flow rates exceeded maximum allowable levels, steam pressures were less than minimum permissible leve1, and stream generator 1 iquid level was below minimum permissible levels).

3. Operators continued the test when plant conditions deviated from prescribed test conditions (test carried out with the reactor power at $200 \mathrm{MW}$ versus the 700 to $1000 \mathrm{MW}$ prescribed level).

Inquiry I.1.1 - Does available evidence indicate that administrative work contro1s impose and effective approach to ensure strict compliance with safety-related requirements, i.e., Technical Specifications, Process Standards, Process Change Authorizations, etc?

Conclusions: Process Standards represent the keystone supporting the structure for administrative control of $N$ Reactor operations. Observance of the provisions and limits set forth in Process Standards documents is heavily emphasized in operator training and in the supervision of operations. There is consistent reflection of this posture from both the Operations and Nuclear Safety lines of management. Maintenance of safety margins is apparent in the hierarchy of operating limits. Process Standards are set up to provide routine operating limits that leave margins to the limits defined in the Technical Specifications, which in turn provide margins to the bounding conditions identified in NUSAR analyses.

The Safety organization currently maintains the Process Standards, which define the permissible operating requires for the Operations staff. Any changes to the Process Standards are subjected to an independent safety review and require approval by both Operations and Safety management. Formal procedures (UNI-M-89, Safety Instruction Manual) govern the processing of major revisions and minor changes. This system provides a mechanisms for operators to work in full compliance by providing a readily available avenue to obtain 
relief from limits that may impose unnecessary operating restrictions. The PCA system allows the operator to propose minor modifications to the Process Standards, with the possibility that approval can occur rapidly. Such a change requires joint approval by the Operations Shift Manager and the Manager, Nuclear Safety for written changes. Approval by Nuclear Safety carries the responsibility to ensure that the change does not transgress any safety basis or Technical Specification limit. While this process provides positive influence for strong administrative control, there is room for certain cautions. In managing the system, it is important to retain the element of two separate, independent judgments applied in granting approval. If the Operations side does not critically evaluate the change to be needed, appropriate and correct, the critical judgment for approval could rest on the Safety approver aloner. The dual responsibility for approval should be continuously emphasized.

One other feature of the PCA approval process emerged as having recognizable value but some potential for vulnerability. Verbal approval of a PCA by the Manager, Nuclear Safety or his delegate can be obtained at offshift periods. Communication by phone or radio is allowed for review (of the written change proposal) and verbal approval by Safety. This could occasionally provide a severe test of memory and judgment should the safety approver be in a remote location.

This review produced a clear sense of a strong, proactive Nuclear Safety management presence and overview of operations compliance with administrative controls. Nuclear Safety staff are present and have a specified overcheck role in the control room for operating sequences involving major reactor systems changes such as startup, scram recovery and critical tests. An example noted was independent calculations by Safety of rod position vs power prediction must compare within acceptable limits with the operations rod withdrawal procedure during startup. Deviation beyond the identified limits imposes a hold until the discrepancy is resolved.

\section{Recommendation:}

- The provisions and practive for oral approval of PCAs should be reviewed to ensure acceptability.

Inquiry I.1.2 - Is there an institutionalized basis for ensuring compliance and detecting deviations that indicates how well administrative controls work and what revisions are needed?

Conclusions: The Nuclear Safety organization has responsibility to review and audit procedure violations, which represents the basis for identifying deviations and corrective actions. The manager of Nuclear Safety has plant shutdown authority. This provides a significant responsibility and authority to influence compliance with procedural controls and operating limits. This authority applies to all safety management up the chain from the Nuclear Safety group. The formal basis for safety overview, review and compliance functions is set forth in UNI-M-89. The safety organization is required to perform periodic reviews and audits. This approach to compliance and the formal reporting of Unusual Occurrences, including violations of technical specifications and limits reflects implementation of the DOE Safety Orders 
and directives to all contractors. One important provision for assessing deviations results from the requirement that Nuclear Safety review the record of each scram event and approve restart. Several members of the Nuclear Safety staff are formally certified, and they provide the coverage of startup and critical maneuvers.

Training given operators is one of the most important influences to ensure compliance with procedures and limits. Both Operations and Safety management stressed that training emphasizes rigorous observation of Process Standards requirements. Safety sign-off is required on individual Operator qualification.

The formal responsibility charged to Operations is to operate the reactor safely and maintain the plant within the Process Standards requirements. The Shift Manager has ultimate control and responsibility over the plant at all times. The Operations management crew consists of:

- Control Room Supervisor (Certified Operator)

- $\quad 109 \mathrm{~N}$ Area Supervisor (Heat transport system)

- $\quad 105 \mathrm{~N}$ Area Supervisor (Reactor area)

- Auxiliary Area Supervisor.

The control room is manned by a crew consisting of a minimum of three at all times during operation, including two certified operators and a Shift Supervisor or Manager. Typical control room staff during routine operations is more like six. Operators rotate on fixed cycles between function stations within the control room. This establishes a basis for continuous cross checks between operators contributing to Process Standard compliance. All operators have simulator training.

There are occasional inefficiencies or problems that arise in Operations because the operators in $109 \mathrm{~N}$ and $105 \mathrm{~N}$ Areas are represented by different unions. Operations management is consciously pursuing a unified working environment by crossover assignment of supervisors and team-building techniques, which should continue.

Inquiry I.1.3 - How does plant management assess adequacy of procedures and level of compliance (i.e., what is the basis for management confidence in correct operations on back shifts)?

Conclusions: In addition to the formal Nuclear Safety audits, references were made in this review to other audits reflecting management initiative. Tracking of Process Standard violations provides a basis to judge the frequency of report of errors. One audit of PCAs approved over the past year concluded that none were inappropriately approved. There was reference to random reviews of procedure check-off sheets. However, this Review Team did not perceive a systematic approach to check up by Operations management to obtain a measure of how well their staff was complying with procedures.

Operations management did project confidence in the capabilities of carefully selected and trained Shift Managers and Shift Supervisors to maintain a high standard of compliance. Training and management philosophy reflect strong 
emphasis on safety and procedures. There appears to be a culture that encourages operators to question each other and their supervision if they think orders or direction may result in violations of Process Standards. The current Operations Manager served previously as Manager, Nuclear Safety, and clearly reflects high sensitivity to safety culture. Institutional provisions that will ensure the continuation of the current operations safety climate with less dependance on individual managers should be pursued.

\section{Recommendation:}

- Operations management should consider implementing a systematic, routine assessment of compliance with procedures by operating personnel, including provision for review of trends indicating unacceptable departure from expected performance.

Inquiry I.1.4 - Are pressures to meet production commitments handled in a way that personnel compliance with safety requirements is not jeopardized?

Conclusions: The emphasis in training on rigorous observance of Process Standards and the management philosophy on safety indicate that safety considerations should be dominant. Management philosophy is that safety problems are costly in both time and dollars. Avoiding safety problems enhances overall productivity. The culture of operators questioning of instructions which they think may make them vulnerable to Process Standard violations is a positive influence. Rotation of staff between safety and operations organizations is a practice that provides positive reinforcement of safety consciousness.

\section{Issue 1.2 Approval of Tests and Other Unusual Operations}

\section{Basis from Chernobyl Events}

1. Plant test document did not address actual hazards and apparently did not establish test-specific limiting conditions.

2. Numerous deviations from safety-related requirements occurred (trip bypassing, deviations from specified requirements, etc.) that were reported by the Soviet report as violations. It is not clear if the deviations were ad hoc and undertaken by individuals in clear violation or if they were sanctioned by a misuse of a plant waivering system.

3. Operator continued tests when plant conditions deviated from prescribed test conditions. It is not clear whether this violated a test document instruction or if the test document failed to provide guidance.

4. The Test Director was not reactor qualified.

5. The Test Director apparently assumed control over plant operations.

Inquiry 1.2.1 - Are procedures for conduct of tests sufficiently formalized to ensure test control, including prior analysis, approvals, and unexpected changes?

Conclusions: There is a strong system for control of tests in $\mathrm{N}$ Reactor. Tests performed in the $\mathrm{N}$ Reactor are prepared and conducted in accordance with instruction SI-6, "Preparation of Production Tests" from the Safety 
Instruction Manual, UNI-M-89. This sets forth requirements for safety analysis, technical bases, operations instructions, limitations and specifications. Review and approval by Nuclear Safety, Operations and up to twelve additional management reviewers is specified. A concern here is that the number of signoffs on the Production Test document may unduly dilute the approval responsibility. A process that brings final approval up to a limited number of key managers would strengthen accountability. The current range of review is probably appropriate, if it supports a more limited final approval.

A11 tests are run within Technical Specification limits. Any changes to Technical Specifications require submittal for review and approval by DOE. This imposes multiple levels of independent contractor organization and review to approve exceeding reactor control limits during tests such as those violated at Chernobyl.

Responsibility for conduct of tests is vested in two "Test Directors, " one of which is from Operations and the other from the technical organization sponsoring the test. Modifications to the test require various signoffs as detailed in the procedures, depending on the type of change. At least two signatures are required in all cases, including the Operations Test Director and Manager, Nuclear Safety. Significant changes that fall outside the original safety review are subjected to the complete original signoff.

During the performance of tests, Operations maintains control of the plant at all times. Safety organization overchecks may be performed during a test activity, at their discretion. Authority to terminate a test at any time is vested in both test directors and also in the Manager, Nuclear Safety.

Production Test instructions (SI-6, UNI-M-89) require that Process Standards which are waived or temporarily changed by the test procedure be tabulated in the Production Test documentation. Incorporation of some notation in the test procedure used by operators wherever test conditions specifically replace a Process Standards limit could further reinforce a climate of total adherence by Operators to the Process Standards.

One other feature of SI-6 that could be strengthened is Section 8, which identifies the requirement to provide the safety and hazards analysis for each test. This statement of requirements is quite general, which leaves the test designer with little in the way of specific guidance on what must be considered for different types of tests. Expansion of this section of SI- 6 to amplify which safety analysis is minimally required to cover different kinds of tests (i.e., at-power test vs irradiation test vs noncritical diagnostics) would strengthen the procedure.

Recommendations:

- Production Test approval should be reviewed, with emphasis on final approval responsibility for both Operations and Safety. The current process based on approval signature by 10 to 12 individuals tends to diffuse responsibility. 
- Section 8.0, "Safety Analysis, Potential Hazards, and Special Precautions" of UNI-M-89, SI-6, should be augmented since it does not provide sufficient detail and guidance to ensure uniform and sufficient treatment of safety concerns.

Inquiry I.2.2 - Do provisions for test performance ensure qualified technical support during test conduct?

Conclusions: The Production Test procedure system relys on the management of the organization initiating the test request, the multiple reviewers who sign off and the final review by the UNC Nuclear and Environmental Safety Committee to ensure adequate technical support for tests. The designated Test Directors (Technical and Operations) are approved as part of the test documentation and procedures. This provides reasonable screening of capabilities, but the selection could be strengthened if a formal definition of qualifications for Test Directors were made part of the governing manual.

A number of practices for test control were reviewed and documented as part of a UNC in-house self audit that was performed in 1985 to Institute of Nuclear Power Operations (INPO) standards. Pretest training of operators is common practice. Test documents and procedures are maintained in the control room while tests are active. The Operations Test Director focuses on plant status and is responsible for maintaining the plant within approved operating limits. He must have operator certification credentials. Shift Managers and Shift Supervisors are usually selected for the role of Operations Test Director.

It was stated during the review that some of the more critical Production Tests were sponsored and designed by the Nuclear Safety organization. These tests were independently overchecked within the Safety organization. A stronger separation of test sponsor from the primary safety review process could eliminate any potential conflict of interests. This situation shall change as a result of organizational restructuring by Westinghouse Hanford Company in conjunction with Hanford Operations and Engineering Contractor takeover.

\section{Recommendations:}

- Test documentation should state requirements on the minimum qualifications for Test Directors.

- There should be organizational separation of the test sponsor from the independent safety approval of Production Tests.

\section{Issue I.3 Bypassing Safety Systems}

\section{Basis from Chernobyl Events}

1. Apparently there were physical provisions for easily bypassing safety features - even with the plant in operation.

2. Safety system bypass was apparentiy regarded by operators as a discretionary action. 
Inquiry I.3.1 - Is the present situation plainly justified or should the bypassing provisions at $N$ Reactor be evaluated in detail to determine if changes should be made?

Conclusions: Based on current operating modes, safety system bypass does not pose an undue risk. Nevertheless, some specific steps and additional evaluation seem appropriate to further decrease potential for mishandling.

A number of bypass switches exist on safety circuits at $N$ Reactor. All switches are located in visible panels, are annunciated with indicator lights and have key locks. It was apparent from this review that the keys for these switches have not been closely controlled.

Specific restrictions are documented in Process Standards to control use of bypass switches for system qualification testing and maintenance. Safety systems are not bypassed at full-power operation, and only two systems require manipulation of bypass during startup procedures. Two of the most critical protective scram systems, overpower and high pressure, cannot be defeated at any time.

Since bypass maneuvers are not done at power, the type of improper operator action that occurred at Chernobyl is improbable. However, a system for rigorous control of bypass switch keys would reduce risks of unauthorized manipulation. An assessment should be made to determine the value of additional measures to reduce risk, such as pulling keys from switches during operation or installation of physical interlocks that would prevent reactor operation with critical functions bypassed. A formal control system, as considered in SEP assessments, should be implemented for safety system bypass switch keys. The feasibility of interlocks that would prevent reactor operation with critical safety functions bypassed should al so be evaluated.

Removal of bypass switches used to isolate systems for maintenance or functional performance checks could impose greater risks than currently exist. Bypassing safety system circuits by jumpers or temporary wiring where status is not immediately visible to operators is highly undesirable.

\section{Issue I.4 Availability of Enqineered Safety Features}

\section{Basis from Chernobyl Event}

1. Scram capability of the Chernobyl RBMK control rods was too slow to terminate the accident after manual trip.

2. Control rod design features resulted in a positive reactivity insertion at the initiation of the scram.

Comment: Engineered safety features have been well covered in prior $\mathrm{N}$ Reactor reviews, in particular the Design Review of June 1986. The key safety system features of $N$ Reactor are described in the design comparison with the Chernobyl RBMK provided in Section II of this report. The availability of two diverse, fast-acting shutdown systems in $N$ Reactor is in marked contrast to the significantly less effective system used in the RBMK. At Chernobyl, the 
shutdown system was rendered ineffective by operator action. Analogous manipulation, resulting in decreased scram effectiveness, is impossible in $\mathrm{N}$ Reactor. Considerations on specific safety systems are brought forward under other issues.

\section{Issue I.5 Operating Staff Attitudes Toward Safety}

\section{Bas is from Chernobyl Events}

1. Actions taken by operators indicated a lack of concern for staying within analyzed operating envelopes and specifications.

Comment: A positive perception of staff attitudes on safety was obtained in the reviews with Operations and Safety management. There was no attempt made in this Lessons Learned activity to develop a broad-based sampling of staff attitudes through interviews or questionnaires. There was consistency in the descriptions of staff training emphasis, staff attitudes toward compliance with Process Standards, and a culture of questioning instructions that do not correspond to the operators' understanding of applicable limits. Conclusions relevant to this issue are provided under other topics above. A separate review, beyond the scope set for this activity, would be needed to thoroughly address this issue. Further assessment in this area should follow from the ongoing interface with INPO targeted to a certification program and as a part of the management activity involved in the Hanford contractor changeover to Westinghouse.

\section{Issue I.6 Management Systems}

Basis from Chernobyl Events

1. The sequence of events leading to the accident implies a lack of clear lines of responsibility for the status and safety of the plant.

2. Directions from an electrical engineer from outside the plant line management were apparently followed by shift personnel even to the extent of violating both standard limits and the test procedure.

3. The test procedure reportedly had little, if any, review by the onsite safety function.

Comment: This Issue was not pursued in detail as part of the inquiry process directed to UNC staff. References were made by staff to various features of the management systems, key features of which are summarized here. The requirements for management systems, including commitments on the implementation of nuclear safety, are defined in UNC's contract with DOE. This provides the legal basis for formal definition of responsibilities for the $N$ Reactor within the contractor organization. UNI-M-100, Company Policy Guide, clearly defines the overall responsibilities of those in various management positions and organizational entities. From this framework, a number of operating manuals spell out specific requirements and procedures for implementing the contractual responsibilities. Examples of these manuals which did enter into this review in various Inquiries were UNI-M-89, Safety Instruction Manual; UNI-M-152, N Reactor Administration Manual; and UNI-M-20, N Reactor Operations Procedures Manual. 
Overlaying this management system within the contractor organization are the DOE Orders pertaining to nuclear safety of DOE facilities. These Orders define requirements representing the basis on which the DOE Environment, Safety and Health organization regulates the safety of DOE operations. Overchecks for compliance are clearly mandated and approval by DOE is required for any significant change to the reviewed Safety Analysis Report covering a reactor facility.

\section{Issue I.7 Accident Management}

Basis from Chernobyl Events

1. Unlike the accident at TMI-2, there was no need to manipulate reactor systems to mitigate accident consequences, since the Chernobyl reactor

2. was completely destroyed in the initial minute of the accident. Reactor Unit 3 at Chernobyl, which shared common generation systems with Unit 4, continued to operate for several hours following the accident.

3. Although the Unit 4 reactor was completely destroyed by the power excursion, plant operators remained on duty and attempted to inject water into the reactor.

Inquiry I.7.1 - What is the basis for managing an accident situation at $N$ Reactor?

Conclusions: Instructions to operators for handling offnormal or accident situations are provided in an Emergency Response Guides document. For various system faults or failures, this document specifies responses that are intended to stabilize the plant and minimize damage consequences. UNC has initiated activity to expand and upgrade the Emergency Response Guides as part of the SEP. The approach will include revision to a symptom-oriented format that is used in emergency procedures for commercial LWR plants. To implement these plans most effectively, UNC could benefit from the experience and perspectives available in the commercial nuclear industry. Working with an outside peer group during the course of preparing the revisions to emergency guides would have greater benefit than just reviewing them when completed.

Within the SEP there is currently in progress an extensive PRA activity. An independent, separate PRA activity sponsored by DOE is being performed at Los Alamos National Laboratory. These studies include consideration of operator actions that can cause system malfunctions or failures in the context of accident initiation. At Chernobyl and at TMI, operators compounded their problems by inappropriate actions. In analyzing severe accidents, useful perspectives can develop from assessing the range of both appropriate and inappropriate operator recovery actions available. Results of such consideration represent a resource of value in the refinement of emergency response procedures and evaluation of scenarios beyond the design basis accidents. For major design basis accidents or for the dominant accident initiators identified in the PRA, operator error is an important element of potential to significantly worsen the accident. The importance of such considerations is recognized in the SEP planning of ongoing severe accident assessments. 
One specific issue that was referenced in this review concerns the most appropriate operator response to a highly improbable case which assumes that the ECCS fails to activate when tripped and some time passes before the system can be activated manually. There is a question on time to a core damage state where initiating ECCS flow might potentially worsen the accident. It is not clear that there is a uniform position in UNC, supported by updated analyses, on the correct instruction to operators for this case. This deserves near term attention to establish a position that has been adequately analyzed, fully reviewed and clearly expressed to management and staff of operations and safety organizations.

\section{Recommendations:}

- Provide for review of the inprocess restructuring of the Emergency Response Guides by a peer group experienced in preparation of equivalent procedures for commercial LWR plants.

- There is a question concerning the exact point at which ECCS activation by manual actions should be implemented or deferred if automatic ECCS trip fails. A clear plan of action for further structured analysis and review is needed to ensure appropriate revision of the Emergency Response Guides along with full communication of the correct procedure to all Operations, Safety and cognizant Technology staff.

Inquiry I.7.2 - What training is provided for operators at $N$ Reactor as preparation to deal with an accident?

Conclusions: Training to the Emergency Response Guides has been a standard part of the operator certification program. An upgrade in operator training for emergency response and accident management is planned as part of the SEP. The enhanced training program will include use of the reactor control simulator, which is not currently configured to provide simulation of accident sequences. This upgrade appears to be directed at providing training equivalent to that recommended by NRC for operators of commercial plants.

At present, the Emergency Response Guides have limited coverage of the measures to maintain emergency flow in the GSCS. In view of the importance of this system to mitigating the consequences of a severe accident, as discussed under Issue III, Containment, greater emphasis should be placed on operator attention to the GSCS in accident situations. This should be included in near-term updates to emergency procedures with related supplemental training.

Recommendation:

- Train operators in the currently recognized significance of GSCS operation in severe accident situations and cover this appropriately in the Emergency Response Guides. 
WHC-SP-0257

MAJOR ISSUE II. DESIGN

Issue II.1 Reactivity Accidents

Basis from Chernobyl Events

1. Accident was initiated when the plant configuration was changed such that a reactivity insertion was generated that was much 1 arger than could occur under normal conditions.

2. Nuclear speed-of-control adequacy depended upon administrative control to prevent excessive rod system withdrawals, which results in decreased response capability. In the Chernobyl accident, reactivity apparently became initially positive at the start of rod insertion.

Inquiry II.1.1 - What basis exists to determine if more severe reactivity insertions are possible than analyzed in NUSAR? Example situations include:

- Cold water injection:

- Offline cell - analyze local effects

- ECCS without scram (consider physics tests carried out using special cooling mode)

- GSCS tube failure without scram

- Void collapse (assumes a credible way to produce voids with reactor at power)

- Malfunction associated with rod withdrawal.

Findings: The inherent neutronic characteristics of the $\mathrm{N}$ Reactor highlighted in this review show no indication of any path to an autocatalytic state. The primary reactivity coefficients, which would dominate the reactor's response to power upsets and transients, are overwhelmingly negative. The coolant void coefficient, which dominated the Chernobyl accident sequence, is sufficiently negative as to be equivalent to insertion of about 20 control rods at $20 \%$ of coolant voided. The largest positive reactivity coefficient is that of the graphite moderator temperature, but the huge thermal inertia associated with the massive graphite blocks precludes this source for rapid power excursion.

The NUSAR analyses of transients that have single or multiple event initiators are reasonably comprehensive. All transient cases identified to date as system malfunctions are terminated by either the primary control rod or the secondary ball drop scram actions without producing fuel failures. Some of these events have been systematically reanalyzed using codes and methods containing recent updates and refinements. Improved methods can also be applied to assess cases beyond the NUSAR design basis envelope, and especially those events which emerge as worthy of consideration from the ongoing PRA activity. A preliminary review indicates that most of the cases identified above (Inquiry statement) are not severe or that these cases are either incredible or of very low probability. Thus, lessons learned from the Chernobyl accident do not establish physics analyses of $\mathrm{N}$ Reactor as a matter of the highest priority.

UNC personnel providing information to the review team described a program under consideration for utilizing newly available analytical codes to improve the safety bases related to nuclear control. These improved tools will enable 
much more accurate modeling of certain accident initiators--such as cold water injection. The new tools will also permit performance of transient analyses that accurately reflect the reactivity consequences of coolant boiling, which has not been previously possible. In short, these new analytical tools will eliminate the need for nonquantitative conclusions on the outcome of certain accidents (e.g., cold water injection from an offline cell). They also will permit establishing the magnitude of reactivity insertions that would result in exceeding damage thresholds, such as fuel melting, permitting quantification of safety margins. The review team concludes that continued modernization of the physics safety bases for the $\mathrm{N}$ Reactor is highly desirable.

Recommendation:

- Updated reactor physics codes should be applied to (re)analyze reactivity insertion events identified as key initiators or contributors to NUSAR or beyond-NUSAR accident scenarios, including definition of margins to important core damage thresholds.

Inquiry II.1.2 - If an insertion event more severe than NUSAR events can be identified, what are the consequences?

Conclusions: Events more severe than those identified in NUSAR appear to require lack of, delay of or only partial scram. Event initiators or faults that would result in this condition have not been identified. In further assessments, some attention should be focused on localized conditions which might involve grouping of several fueled tubes (e.g., 2 to 20) or regions defined by the influence of several control rods, etc. The considerations under Issue II. 5 should also be recognized.

Issue II.2 Accidents at Low Power and When Shut Down

Basis from Chernobyl Events

1. Event was initiated from a low power (200 MWt).

2. Proceeding events had placed reactor in an unanalyzed condition (low power, high coolant flow, rod withdrawals in excess of technical specifications).

Inquiry II.2.1 - What analyses address potential offnormal reactor conditions involving low power as related to flow and rod position?

Conclusions: A number of transients from low power, including rod withdrawals, are analyzed in NUSAR. Low power, high flow reactivity transient events should be covered in the continuing search for bounding reactivity events as recommended in II.1.1.

Inquiry II.2.2 - In what ways could the reactivity control system be disabled during outages? Evaluate startup practices to determine credibility of timely detection.

Conclusions: All work during outages is performed under maintenance procedures that must be approved by Nuclear Safety. If any portion of the shutdown protective system were disabled, this would be detected before start-up during 
the functional tests that are part of the Mandatory Check Lists which must be used for startup. Since bypass switches are annunciated with panel light indicators in the control room, systems disabled by this method would be immediately obvious.

\section{Issue II.3 Multiple Units (Not Applicable to N Reactor)}

Issue II.4 Fires (Addressed as Issue VI)

Issue II.5 Multiple Tube Integrity

Basis from Chernobyl Events

1. The reactor cavity disruption occurred from a large steam release to the cavity, apparently because of simultaneous or near simultaneous rupture of a large number of pressure tubes.

2. Reactor cavity disruption may have exacerbated the event by pulling control rods out again and severing remaining tubes.

Inquiry II.5.1 - What are the implications of single and multiple pressure tube ruptures in $\mathrm{N}$ Reactor?

Conclusion: The design basis for $N$ Reactor includes the requirement for capability to accommodate the failure of a single pressure tube without damage to other reactor systems. NUSAR addresses the effect of single tube rupture on reactivity control systems. These analyses show that shutdown capability is retained following such an event. Also, the pressure pulse from blow-down of a failed tube can be accommodated without damage to the shields enclosing the graphite stack. The reactor is not designed to accommodate the failure of multiple pressure tubes. Such an event could potentially damage the biological shield, altering the geometry such as to introduce uncertainties on the functional capabilities of other safety systems. Thus, it is necessary to demonstrate that rupture of a single pressure tube cannot propagate to a multiple tube rupture event. Analyses on the margins to structural damage of the biological shield are part of the SEP, and provide additional assessment of hypothetical cases beyond the design basis accidents. These analyses should be completed in parallel with the ongoing PRA activity.

Inquiry II.5.2 - What is the basis to exclude multiple pressure tube ruptures in $\mathrm{N}$ Reactor?

Conclusion: The initial defense against multiple tube ruptures is to minimize the probability of failure for any single pressure tube. Design and specification of the original pressure tubes for $N$ Reactor included the requisite conservatism to meet or exceed industry pressure vessel code standards. A surveillance program was conducted to characterize the effects of irradiation and service conditions on the structural properties of the pressure tubes. This ensures that inservice changes are properly considered and fall within the design and analysis envelope. Ultimately, this safety case rests on structural analyses that show that pressure tube rupture propagation cannot occur. Studies have been performed and updated several times since $N$ Reactor 
started operation in 1963, including analyses representing the design basis given in NUSAR. The most current assessments have been performed by IMPELL Corporation for UNC. Validation of these analyses through independent review is part of the current Westinghouse assessment of the SEP.

Recommendation: Complete reviews that establish an independent verification that pressure tube rupture will not propagate to other tubes (before restart for full-power operation).

Inquiry II.5.3 - What has been done to ensure service-induced aging of pressure tubes does not compromise the safety basis for protection against multiple tube rupture?

Conclusion: A surveillance program has been in place for some time to provide in-situ inspection and periodic removal and destructive examination of pressure tubes. The scope of the program has recently been expanded for application of nondestructive (ultrasonic and eddy current) testing along with an expanded program of mechanical property and burst testing. A program of mechanical property testing and characterization of samples from high-exposure tubes removed from the reactor in February 1987 is currently in progress. Additional work has started, involving accelerated irradiation of tube specimens to assess both neutron fluence and chemical corrosion effects. These data will lead the $N$ Reactor tube exposures by several years when results become available in 1992. Results of the characterization program must be utilized in a close coupled manner for updating and reverifying the analyses that demonstrate that rupture propagation will not occur.

\section{MAJOR ISSUE III: CONTAINMENT}

Basis from Chernobyl Events

1. The accident at Chernobyl completely bypassed the confinement system.

2. Given the nature of the forces involved in destruction of the reactor caused by autocatalytic power excursion and steam pressure, it is not clear what type of reactor containment structure would have remained intact.

NOTE: Because of the unique character of the $N$ Reactor confinement system with filtered venting, the specific NRC Containment Issues (III.1 Beyond DBA Capabilities and III.2 Filtered Venting) were not addressed separately. Also, the $N$ Reactor's remote location (35 miles from the nearest population center) is recognized as adding an isolation factor not considered in commercial reactor containment requirements.

Inquiry III.1 - What possible events might compromise $N$ Reactor confinement integrity, and what is their probability?

Findings: The most relevant perspective on confinement integrity is that associated with the lack of a mechanistic basis for a high-energy, autocatalytic reactivity insertion accident. In the absence of an overpower 
transient capable of overpressurizing the confinement, the issues related to Combustible Gas (V.3) and Multiple Tube Rupture (II.5) are recognized as relevant to the question of confinement effectiveness. Resolution on the status of these two issues, per their respective discussions, effectively disposes of these considerations. Dominant accident sequences and reliability of specific equipment are being determined in the ongoing PRA activities. This effort will provide a more definitive basis for projecting confinement reliability and effectiveness.

The SEP includes extensive testing, currently in progress, to ensure that the confinement system will work as designed. Additional equipment qualification update activity covers confinement and other related safety systems, such as ECCS and GSCS. These latter two systems are also undergoing tests while some features of the systems, such as isolation of pumps and water sources to protect from common-mode failure, are being constructed. It is the combination of these cooling systems with confinement that represents the envelope of severe accident containment.

Although accident mitigation systms were not a factor in the Chernobyl events, the characteristics of such systems are important in limiting the consequences of different severe accidents. The GSCS is an independent back-up reactor cooling system unique to $\mathrm{N}$ Reactor. This system leads to a predictable, stable core and confinement system configuration, even if the ECCS fails. The bounding design basis accident, which is being reanalyzed with updated analysis tools in the SEP, is stabilized and terminated without the ECCS as long as the GSCS is operationally effective. Some of the important features of the GSCS, being confirmed as part of ongoing SEP analysis updates, are as follows:

- Stabilization of the core is possible before core geometry is altered by pressure tube melt-through.

- Postaccident fission product release scenarios are simpler and hence more dependably predicted.

- Large thermal inertia of the graphite stack allows time for GSCS adjustment or recovery operations, enhancing availability of the system.

- The GSCS, with its indirect cooling, avoids direct contact between failed fuel and cooling water in recovery operations.

Thus, the combination of the GSCS and the confinement systems provides for preserving the core structural configuration and for entrapment of fission products that may escape the core. This represents an effective accident containment posture, covering the unlikely scenarios of an accident where the core is not or cannot be reflooded by the ECCS. In a commercial LWR plant, the final defense against release of radioactive material in an accident scenario where the ECCS is ineffective (e.g., TMI-2 where operators turned off the ECCS) is the reactor containment structure. For $N$ Reactor, the GSCS plus the confiner provide a level of protection from accident consequences that is analogous to the containment system of a commercial LWR plant.

Because of the recognized importance of the GSCS, SEP and independent equipment qualification evaluations are focused on establishing full credibility for the GSCS as a safety system. 


\title{
MAJOR ISSUE IV. EMERGENCY PLANNING
}

\author{
Basis from Chernobyl Events \\ 1. Delayed evacuation resulted in higher than necessary offsite doses. \\ Contamination of evacuation routes contributed to delays. Massive use \\ of a polymer apparently reduced contamination spread problems. Use of \\ KI pills apparently was effective. \\ 2. Emergency plans did not address accidents as severe as actually \\ encountered. \\ 3. Protection of emergency crews was inadequate, including inadequate \\ dosimetry.
}

NOTE: The specific issues from the NRC 1 ist (IV.1 EPZ Size, IV.2 Ingestion Pathway Measures, and IV.3 Decontamination and Relocation) were not addressed separately in this review. The remote location of the $\mathrm{N}$ Reactor imposes a unique character for emergency planning relative to most commercial plants.

Inquiry IV.1 - Assuming an accident occurred that led to a prompt release of radioactivity, what process would be followed in arriving at a decision to evacuate? How long would it take?

Conclusions: The Operations Shift Manager is designated the ERD with responsibility for the initial actions in dealing with an emergency or accident. He would make a decision on evacuation as soon as information was available. His duties at this time would also include notification of senior management and emergency response teams using an ADEX-G automatic dialup system. Activation of the evacuation alarm would take several minutes. If a rapid decision is required, he may or may not have the benefit of consultation with senior management or expert staff. It is not clear what assumptions or guidelines are provided the ERD for a case that might have minimal lead time for a decision.

Recommendation:

- Review the range of responsibilities and the possible decision scenarios that might be thrust upon the Shift Manager in his role as ERD to ensure he has adequate guidance or outside support.

Inquiry IV.2 - What steps have been taken to ensure that plant management would be able to organize an effective response to an accident, particularly one differing importantly from the NUSAR accidents?

Conclusions: UNC has a company Emergency Plan (UNI-M-2) based on DOE Orders and UNC company policies. This plan identifies emergency organizations, roles and responsibilities, as well as provisions for maintaining emergency preparedness. The plan is based on the ability to adequately respond to any and all emergencies involving UNC facilities and is separate from plantspecific response to NUSAR-type accident scenarios. In addition, the DOE, in conjunction with Washington State and local county offices of Emergency Management, has developed emergency plans to coordinate offsite evacuations, 
mutual aid agreements, etc. The Accelerated Safety Enhancement Program is addressing capability upgrade to provide for accident management by operators should the control room be subjected to inhospitable conditions. Temporary control room habitability measures and a remote shutdown capability will be in $\mathrm{place}$ in $105 \mathrm{~N}$ by July. Upgrades to commercial plant standards are in a longer range program (1988 completion).

UNC currently has approval to use KI during accidents involving high radioactive iodine emissions. This drug is located in various stations around $100 \mathrm{~N}$, as well as in Radiation Protection vehicles. A fibra-film truck is available in the 200 Area for use in fixing contamination to contaminated surfaces or equipment.

Inquiry IV.3 - Does emergency planning encompass accidents equal or more severe than the NUSAR hypothetical accident? Has an accident been considered that produced significant radiation levels in the Tri-Cities?

A series of action levels have been identified based on dose rates, projected dose consequences, hazardous material exposure levels, and $\mathrm{plant} / \mathrm{safety}$ system degradation factors. These action levels, when reached, will trigger various offsite responses, independent of UNC onsite response, by State and County Emergency Management personnel. Emergency radiation monitoring equipment has been installed at $100 \mathrm{~N}$ that transmits data to the Emergency Response Center (ERC) located on Rattlesnake Mountain. Longer term emergency management activity would be directed by senior staff from the ERC.

The hypothetical accident has potential for significant dose rates in the Tri-Cities. This scenario would fall under the umbrella of public emergency planning in place for the WNP-2 plant.

Inquiry IV.4 - What provisions are in place for protection of emergency crews?

Conclusions: The Hanford Site emergency crews are well trained and well equipped. Programs of training are systematic and cover major aspects of radiation worker training as well as basic fire fighting or security furctions. Prefire $p l a n s$ and building tours are used to familiarize fire crews with facilities. All emergency vehicles carry respiratory equipment capable of handling chemical and radiological hazards for crews. Fire protection equipment carries individual personnel dosimetry and radiation-metering equipment. Overall preparedness and capability is significantly beyond that available to handle emergencies in the public sector.

Inquiry IV.5 - Are there specific plans for fighting a conventional fire in high radiation/contamination zones?

Conclusions: The Hanford Fire Department Training Manual, Section 16, "Radiological Safety During Rescue and Fire Control," provides instructions for fighting fires under those conditions. 
Inquiry IV.6 - Are preparations adequate for responding to a very severe accident that includes an early fission product release? This considers. both onsite responses and protection of the public.

Conclusions: UNI-M-2 (Vol. 1, Emergency Plan), DOE-RL Emergency P1 ans, and various State and County Emergency Procedures are in place to respond in the unlikely event of a serious accident at $\mathrm{N}$ or any other onsite reactor.

There is no event currently identified in $\mathrm{N}$ Reactor Safety analyses that would produce an early release of significant quantities of fission products.

MAJOR ISSUE V. SEVERE ACCIDENT PHENOMENA

Issue V.I Source Terms

Basis from Chernobyl Event

1. Source terms from Chernobyl event were very large.

Inquiry V.1.2 - What bearing does the Chernobyl radiation release information have on the N Reactor safety basis?

Conclusions: The Chernobyl release must be viewed as resulting from both very high temperatures in the core rubble, extensive mechanical disruption and dispersal of core material and the large draft "chimney effect" that followed the total disruption of that particular reactor configuration. There is no accident sequence that could produce an equivalent disruption of $N$ Reactor; there would be some confinement even in the lowest probability event sequences. Because of the horizontal arrangement of pressure tubes, Chernobyl fission product release rates and magnitude are not pertinent to $\mathrm{N}$ Reactor accident scenarios with mechanistic initiators.

The character of the source term from Chernobyl may have been influenced by the chemical environment in the disrupted core (see Nuclear Safety). For $\mathrm{N}$ Reactor, mechanistic source term derivations consider primarily steam saturated, primary cooling system environment. Analyses should also consider the chemical species that might arise from failed fuel and volatile fission products in contact with hot graphite. Such scenarios might arise in consideration of accidents outside the design basis.

\section{Issue V.2 Steam Explosions}

Basis from Chernobyl Event

1. While not a classic "steam explosion," the fragmentation of fuel in Chernobyl caused a large steam generation, probably accelerating water slugs that may have caused or contributed to multiple pressure tube failure.

Inquiry V.2.1 - What possibility exists for causing water-hammer type loads on the $N$ Reactor pressure tube ends? 
Conclusions: As an initiating factor for severe accidents, water-hammer would be important as a contributor to multiple pressure tube failures. This loading mechanism, as well as thermal shock from cold coolant entry, is a recognized consideration as part of the pressure tube failure propagation assessment. Assessment of water-hammer resulting from the core reflood by the ECCS is currently in progress under the SEP. Consideration of water-hammer should also be included in the ongoing assessments in the PRA work, as related to conditions that might result from inappropriate operator response to a failure event.

Inquiry V.2.2 - What possibility exists for energetic fuel coolant interaction in $\mathrm{N}$ Reactor?

Conclusions: Fuel coolant interaction is not an issue for any $N$ Reactor accident scenario identified. Melting the fuel material in the presence of water, as happened at Chernobyl, cannot occur in the absence of an autocatalytic power excursion. Such a condition has been shown to be precluded by the inherent reactivity feedbacks in $N$ Reactor. The only point of concern for fuel-coolant effects is the chemical reaction that contributes to the hydrogen source term (Issue V.3).

Issue V.3 Combustible Gas

Basis from Chernobyl Events

1. The Soviets claimed the second explosion heard at Chernobyl was a hydrogen explosion.

Inquiry V.3.1 - What is the potential for hydrogen production in $\mathrm{N}$ Reactor?

Conclusions: Extensive evaluations of the Chernobyl accident by nuclear reactor analysts in this country, using state-of-the art analysis tools, indicate that the hydrogen played no role in the explosive disassembly of the Russian reactor. Russian scientists who directed robotic surveillance devices during the cleanup reported seeing no evidence of a hydrogen burn.

Hydrogen does not appear to represent a significant area of uncertainty or risk for $N$ Reactor safety. Review of the $N$ Reactor design basis accident for hydrogen source term suggests there is significant conservatism in bounding the hydrogen yield. Extensive peer reviews of the analyses for hydrogen source have been part of this program. Current estimates of a source term twice the amount previously identified in NUSAR should be conservative as long as the GSCS and the reactor shield structure have not been compromised. This assumption is reasonable since it is addressed under other Issues (II.5 and III). The formal position on hydrogen yield pertains primarily to hydrogen accommodation without risk to confinement. The very large volume of the confinement structure and the inherent mixing effects shown by analysis indicate large margins to hydrogen concentrations which could burn or explode. A means by which hydrogen could contribute to core disruption in the early stages of an accident is not apparent due to inert gas purge of the graphite stack and the influence of steam blanketing on flammability following a pressure tube rupture event. 
WHC-SP-0257

Inquiry V.3.2 - What provisions have been made/planned for dealing with hydrogen?

Conclusions: Application of state-of-the-art analysis codes (HECTR and COBRA$\mathrm{NC})$ to hydrogen distribution and mixing in the $N$ Reactor confinement structures indicate hydrogen/air ratios below flammability limits at all locations. The effect of the confinement spray system is to further enhance circulation patterns that promote dispersion and low concentrations. The one location where hydrogen might preferentially concentrate is the pressurizer penthouse structure. Although the combination of conditions under which ignition could occur in the penthouse is unlikely to occur, the limited margin will be backed up with a mitigation system. A system for hydrogen detection and mitigation is being designed with installation planned during 1987. A design review of these systems has been structured to include participation by both onsite and offsite experts in this area.

Based on what is now known about the causes of core and plant destruction at Chernobyl, and the updated information on hydrogen generation/distribution in $N$ Reactor, hydrogen explosion becomes a nonissue for this review.

\section{MAJOR ISSUE VI. GRAPHITE-MODERATED REACTOR (FIRES)}

Basis from Chernobyl Events

1. Graphite fire began 18 to 24 hours after initial transient.

2. No procedures were in place to deal with it.

3. Procedures were developed during the event. Early attempts at water quench apparently failed, allowing the core to burn for some time. Final ad-hoc procedures involved $N_{2}$ feed from below and covering core debris with material. Initial effect was to heat up core further.

Inquiry VI.1 - What is the potential for obtaining conditions conducive to a graphite fire in $\mathrm{N}$ Reactor?

Conclusions: The graphite stack is protected by a helium cover gas contained within the shield structure. Combustion cannot occur unless the shield structure is sufficiently damaged to leak inert gas faster than available makeup supply. Should that occur, the rate of oxidation would be very slow because graphite temperatures would remain below the threshold for rapid oxidation because of heat removal from the stack by the ECCS or the GSCS. The GSCS alone is capable of removing both decay heat and any heat load from graphite oxidation, stabilizing temperatures in a range which ensures control.

In the Chernobyl accident sequence, the plant was effectively destroyed and conditions for exothermic chemical reactions involving a number of core materials were present before graphite fire made any contribution. It is likely that the major contribution from graphite was to serve as a refractory container for decay heat buildup, zirconium oxidation along with carbothermic reduction of the $\mathrm{UO}_{2}$, and complex gas producing redox reactions. For any $N$ Reactor accident where the GSCS and biological shield are intact, there is 
no way to achieve ignition of the graphite. It has been demonstrated experimentally that oxidation nuclear grade graphite takes very high temperatures to initiate, and the contribution to total heat load is only a small fraction of the decay heat.

Inquiry VI.2 - What analys is has been done?

Conclusions: Detailed reaction rate models have been developed to analyze graphite oxidation. These models tend to show that graphite oxidation in $N$ Reactor would be 1 imited both by available oxygen and the requirement that a high-temperature source $\left(>1100^{\circ} \mathrm{C}\right)$ be available to drive a significant

reaction. The analyses have effectively shown that graphite will not contribute significant accident heat loads.

Inquiry VI.3 - What procedures are in place to deal with a fire?

Conclusions: The availability of the confinement spray system constitutes a significant source of cooling water to combat a fire in confinement. Specific procedures have been developed to deal with emergencies involving graphite fires. These procedures will be part of operator training in revised emergency procedures, which will be completed before restart. 
WHC-SP-0257

\section{RECOMMENDATIONS}

This section pulls up the recommendations listed with Inquiry and Conclusions in Section IV to make them more accessible. These recommendations address refinements to, or reinforce ongoing activities in, the $\mathrm{N}$ Reactor SEP. Changes to organization structures and management systems involved with the Hanford Operations and Engineering contract changeover to Westinghouse provide a context for most of the recommendations. Those recommendations which the Review Teams regard as important to the safety position for $\mathrm{N}$ Reactor restart are indicated with an asterisk.

\section{NRC Issue Area: I. OPERATIONS (ADMINISTRATIVE CONTROLS)}

\section{Recommendations:}

* The provisions and practice for oral approval of PCAs should be reviewed to ensure acceptability.

- Operations management should consider implementing a systematic, routine assessment of compliance with procedures by operating personnel, including provision for review of trends indicating unacceptable departure from expected performance.

- Production Test approval should be reviewed, with emphasis on final approval responsibility for both Operations and Safety. The current process based on approval signature by 10 to 12 individuals tends to diffuse responsibility.

- The following recommendations are intended to further strengthen the control of test operations reflected in current procedures:

- Test documentation should state requirements on the minimum qualifications for Test Directors.

- Section 8.0, "Safety Analysis, Potential Hazards, and Special Precautions" of UNI-M-89, SI-6, should be augmented since it does not provide sufficient detait and guidance to ensure uniform and sufficient treatment of safety concerns.

- There should be organizational separation of the test sponsor from the independent safety approval of Production Tests.

* There is a question concerning the exact point at which ECCS activation by manual actions should be implemented or deferred if automatic ECCS trip. A clear plan of action for further structured analysis and review to resolve this issue is needed to ensure appropriate revision of the Emergency Response Guides and full communication of the correct procedure to all Operations, Safety and cognizant Technology staff. 
* Train reactor operators in the currently recognized significance of the GSCS in severe accident situations and cover this appropriately in the Emergency Response Guides.

- Provide for review of the inprocess restructuring of the Emergency Response Guides by a peer group experienced in preparation of equivalent procedures for commercial LWR plants.

\section{NRC Issue Area: II. DESIGN}

\section{Recommendations:}

* Complete reviews to establish an independent verification that pressure tube rupture will not propagate to other tubes (before restart for ful1power operation).

- Updated reactor physics codes should be applied to (re)analyze reactivity insertion events identified as key initiators or contributors to NUSAR or beyond-NUSAR accident scenarios, including definition of margins to important core damage thresholds.

NRC Issue Area: IV. EMERGENCY PLANNING

\section{Recommendations:}

- Review the range of responsibilities and the possible decision scenarios that might be thrust upon the Shift Manager in his role as ERD to ensure he has adequate guidance or outside support. 


\section{BIBLIOGRAPHY}

DOE-NE-0076 "Report of the U.S. Department of Energy's Team Analyses of the Chernobyl-4 Atomic Energy Station Accident Sequence," U.S. Department of Energy Assistant Secretary for Nuclear Energy, November 1986.

NUREG-1250 "Report on the Accident at Chernobyl Nuclear Power Station," U.S. Nuclear Regulatory Commission, February 1987.

UNI-M-89 S\&EE Safety Instruction Manual, UNC Nuclear Industries, Richland, WA, Safety and Environmental Engineering Department, SI-6, "Preparation of Production Tests," July 1980.

UNI-M-100 Company Policy Manual, Staff, UNC Nuclear Industries, Inc., Richland, WA, March 1977.

HW-76500 "N Reactor Process Standards," Process Standards Subsection, UNC Nuclear Industries, Richland, WA, April 1975.

UNI-M-152 N Reactor Administrative Manual, Staff, Reactor Administrative and Control, UNC Nuclear Industries, Richland, WA, February 1984.

UNI-M-20 N Reactor Operations Procedure Manual, A.P. Vinther, UNC Nuclear Industries, Richland, WA, April 1975.

UNI-M-2 Emergency Plan, UNC Nuclear Industries, Richland, WA.

Volume 1 "Emergency Preparedness Manual," Environmental and Occupational Safety Section, September 1980.

Volume 2 "Emergency Response Guides," Reactor Operations, January 1981.

Volume 5 "Emergency Action Guides," Environmental and Occupation Safety, July 1982 .

"Radiological Safety During Rescue and Fire Control," Tab 16, Hanford Fire Department Training Manual, Richland, WA.

"Emergency Plans," U.S. Department of Energy, Richland, WA.

Nuclear Safety D. A. Powers, T. S. Kress, and M. W. Jankowski, "The Chernobyl Source Term," pp. 10-28, January - March 1987. 


\section{DOE Orders}

5480.1

5480.6

5481.1B
ES\&H Program for DOE Operations

Safety of Department of Energy-Owned Nuclear Reactors

Safety Analysis and Review System 


\section{ONSITE DISTRIBUTION}

No. of

Copies

2

25
Addressee

DOE-RL

KR Absher

DM Smith

Westinghouse Hanford Company

ET Weber (10)

JW Hagan (10)

Central Files (2)

Documentation (2)

Microfilm Services
Mail Stop

A6-55

A6-90

$\mathrm{N} 1-28$

$\times 5-04$

L8-04

L8- 15

L8-15

Distr-1 